2012

\title{
Workplace Discrimination and the Perception of Disability
}

William Draper

Virginia Commonwealth University

Follow this and additional works at: https://scholarscompass.vcu.edu/etd

Part of the Medicine and Health Sciences Commons

(C) The Author

\section{Downloaded from}

https://scholarscompass.vcu.edu/etd/2876

This Dissertation is brought to you for free and open access by the Graduate School at VCU Scholars Compass. It has been accepted for inclusion in Theses and Dissertations by an authorized administrator of VCU Scholars Compass. For more information, please contact libcompass@vcu.edu. 
Workplace Discrimination and the Perception of Disability

A dissertation submitted in partial fulfillment of the requirements for the degree of Doctor of Philosophy at Virginia Commonwealth University

\author{
by
}

William R. Draper, M.S.

Virginia Commonwealth University - Richmond, 2005

Director: Christine Reid, Ph.D. Professor, Department of Rehabilitation Counseling

Virginia Commonwealth University

Richmond, VA

June, 2012 


\section{Acknowledgements}

"Milner's star-tracing experiment with H.M. was the first time a scientist had uncovered the biological basis of a psychoanalytic hypothesis. By showing that a person who has no hippocampus (and therefore no ability to store conscious memories) can nonetheless remember an action, she validated Freud's theory that the majority of our actions are unconscious."

--Eric Kandel (2006). In Search of Memory: The emergence of a new science of mind, p, 133.

"The psychological unconscious documented by latter-day scientific psychology is quite different from what Sigmund Freud and his psychoanalytic colleagues had in mind in fin de siècle Vienna. Their unconscious was hot and wet; it seethed with lust and anger; it was hallucinatory, primitive, and irrational. The unconscious of contemporary psychology is kinder and gentler than that and more reality bound and rational, even if it is not entirely cold and dry."

--J.F. Kihlstrom, et al. (1992). The psychological unconscious: Found, lost, and regained. American Psychologist, 47(6), p.789. 


\section{Table of Contents}

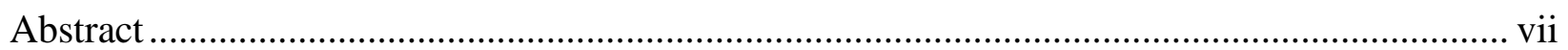

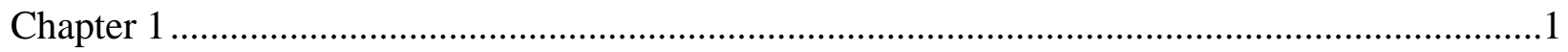

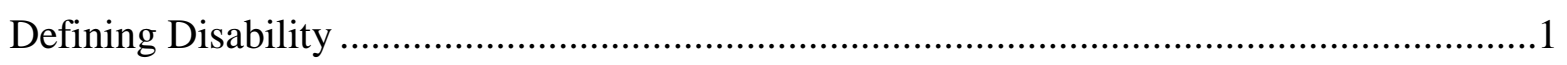

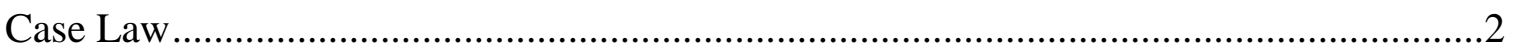

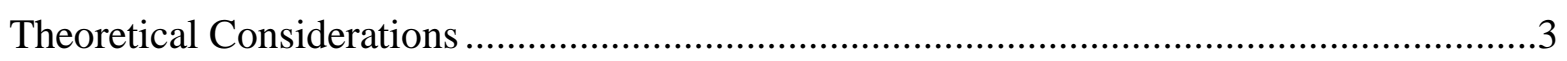

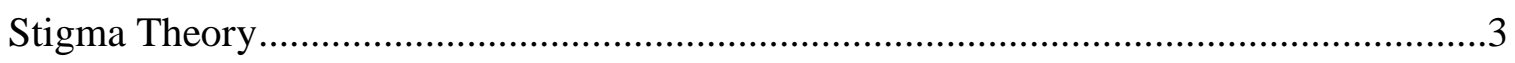

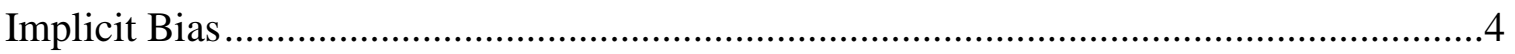

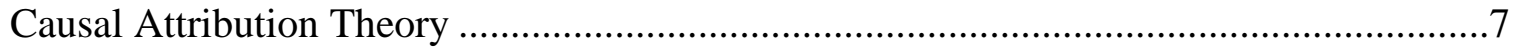

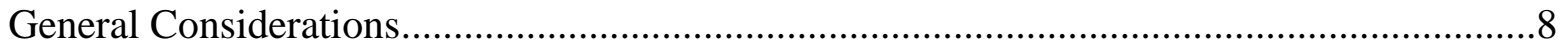

ADA Amendment Act .................................................................................

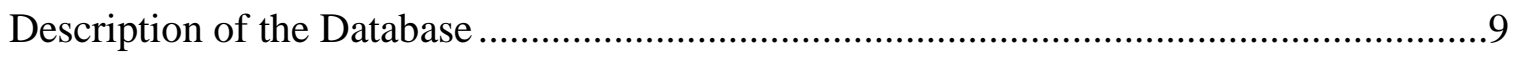

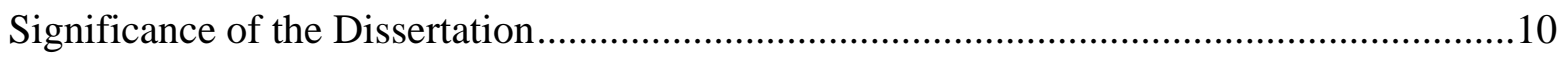

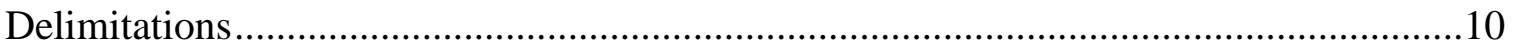

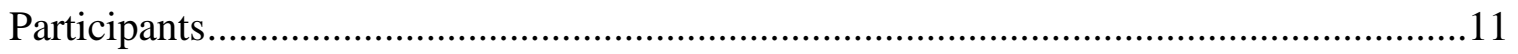

Data Collection and Proposed Analysis ................................................................. 12

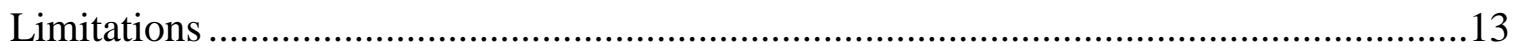

Paper I: Workplace Discrimination and the Perception of Disability ................................13

Paper II: Workplace Discrimination and the Record of Disability .................................13

Paper III: ADA Perceived Disability Claims: A Classification Analysis ...........................14

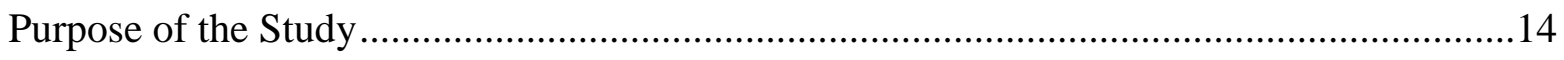


Chapter 2: Workplace Discrimination and the Perception of Disability ..................................15

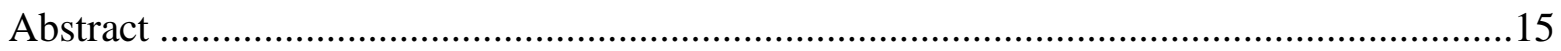

Workplace Discrimination and the Perception of Disability........................................16

Perceived Disabilities: Theoretical Considerations....................................................17

The National EEOC ADA Research Project ...........................................................23

Research Questions about the "Regarded as disabled" Prong ..........................................23

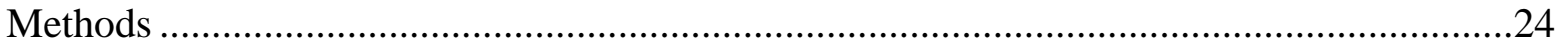

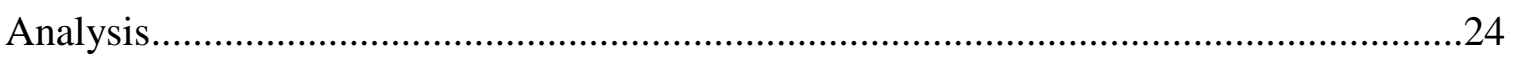

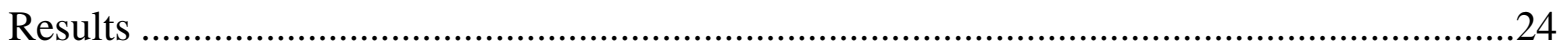

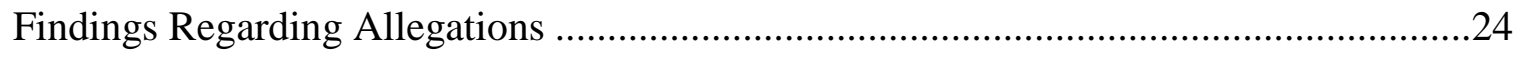

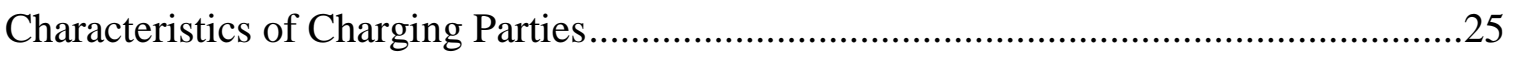

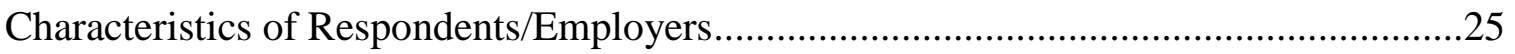

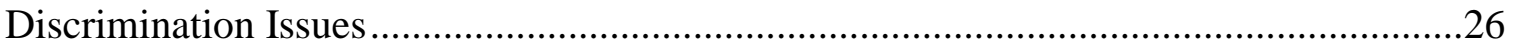

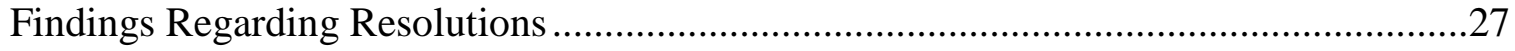

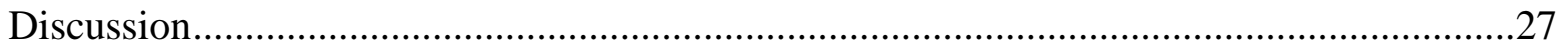

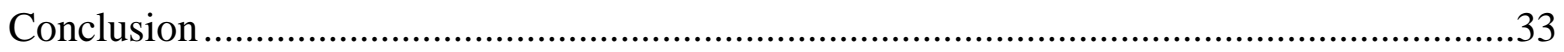

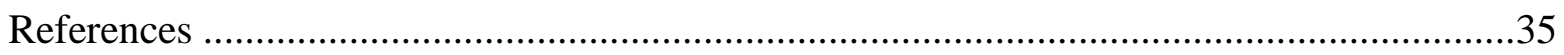

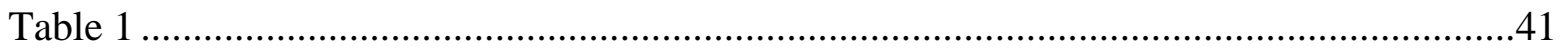

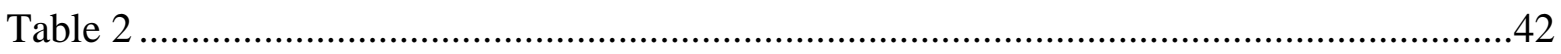

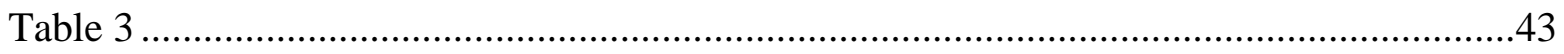

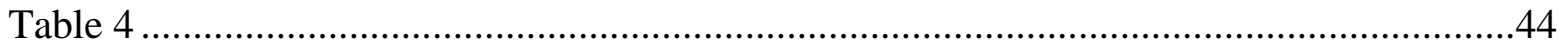

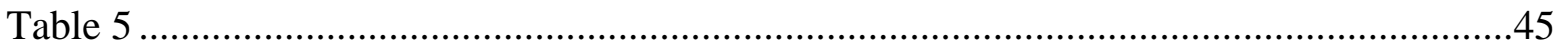

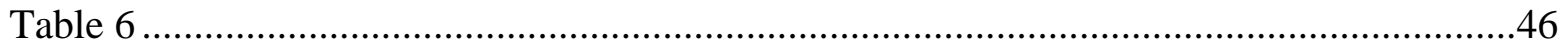

Chapter 3: Workplace Discrimination and the Record of Disability .....................................47 


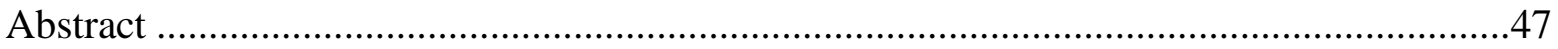

Workplace Discrimination and the Record of Disability ..........................................48

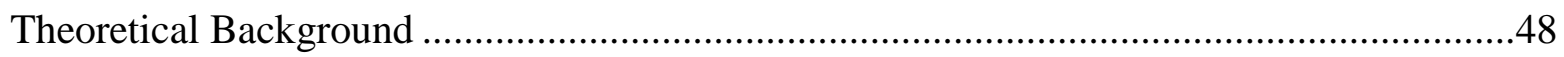

Record of Disability and the ADA Amendments Act ..............................................50

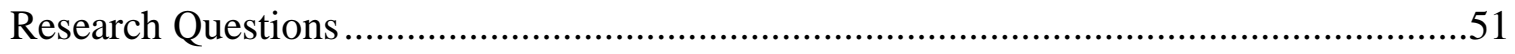

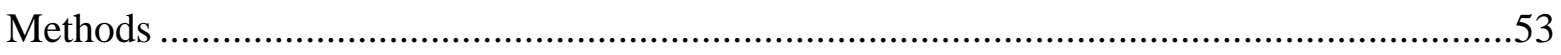

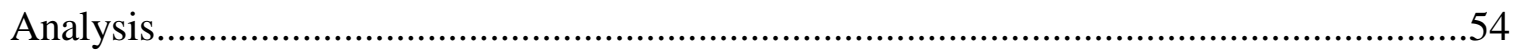

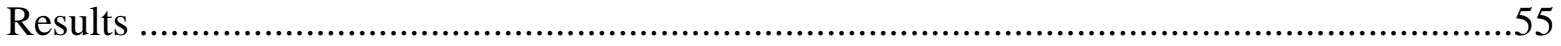

Characteristics of the Charging Parties ..............................................................55

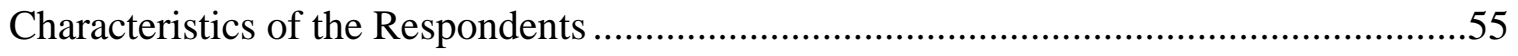

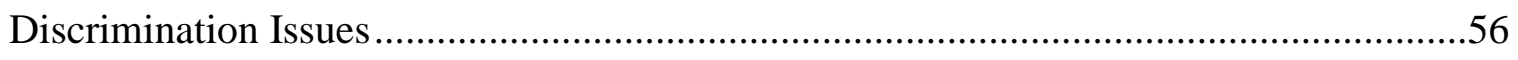

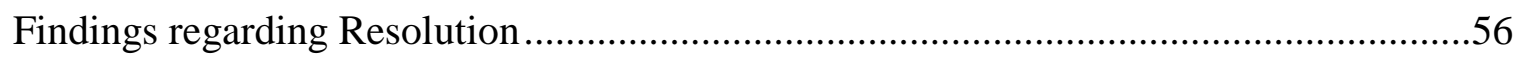

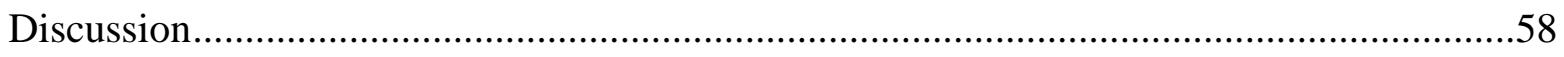

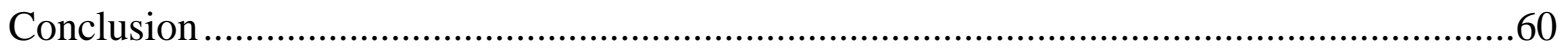

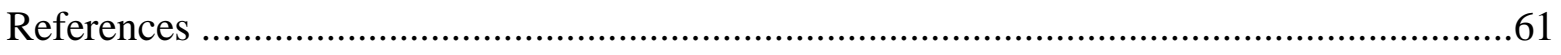

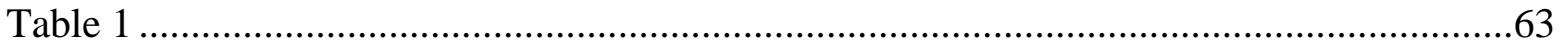

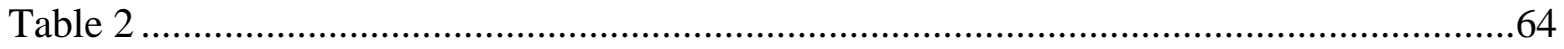

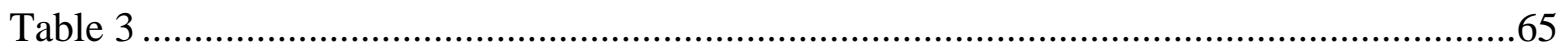

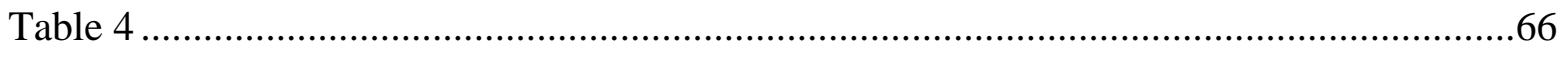

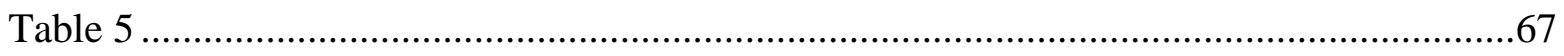

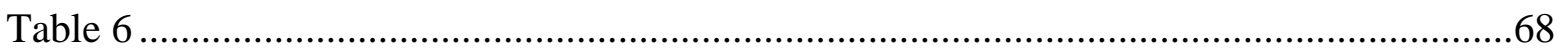

Chapter 4: ADA Perceived Disability Claims: A classification tree analysis ............................69

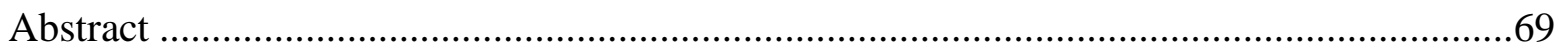

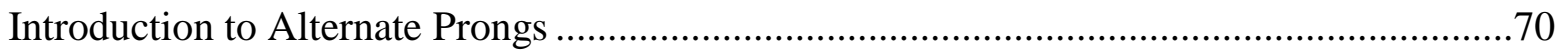




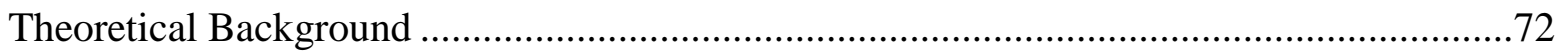

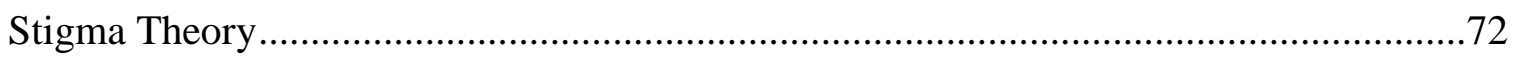

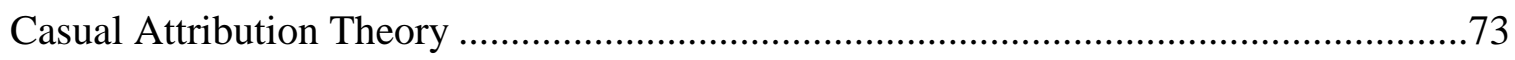

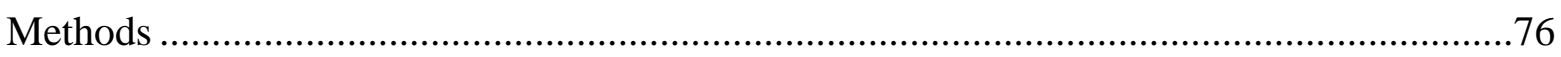

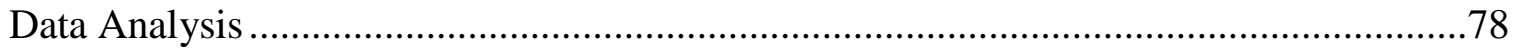

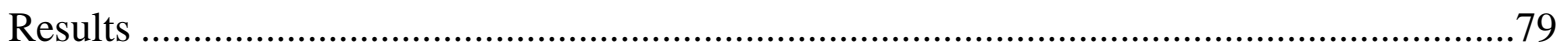

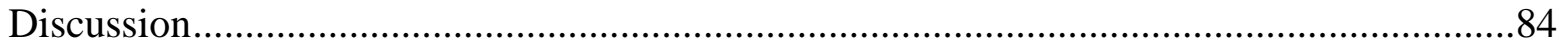

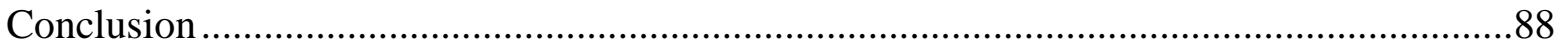

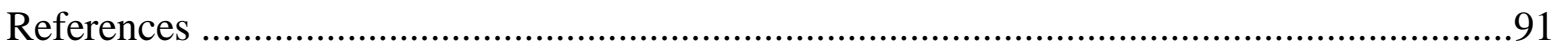

Figure 1: CHAID tree: Split half view of left branch..................................................98

Figure 2: CHAID tree: Split half view of right branch..............................................99

Table 1: Charging Party \& Employer Demographics ..................................................100

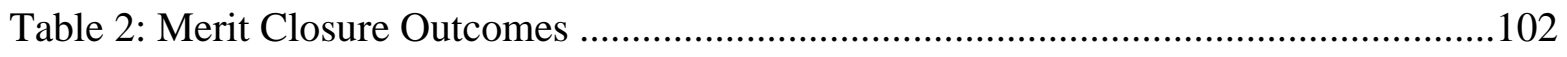

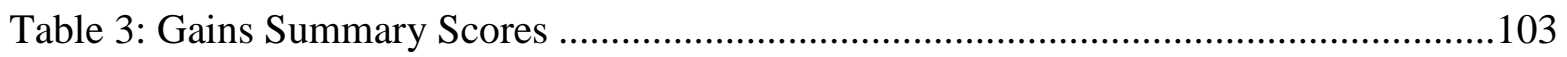

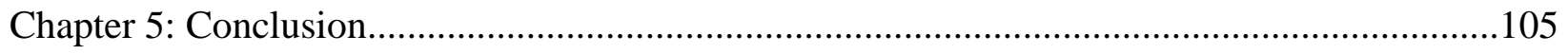

Summarizing the Alternate Prongs Articles ........................................................ 106

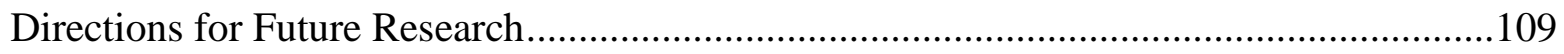

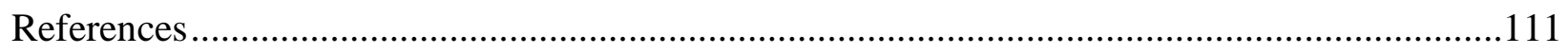

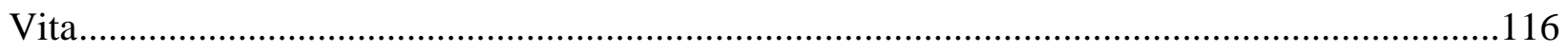




\begin{abstract}
WORKPLACE DISCRIMINATION AND THE PERCEPTION OF DISABILITY

By William R. Draper, M.S.

A dissertation submitted in partial fulfillment of the requirements for the degree of Doctor of Philosophy at Virginia Commonwealth University
\end{abstract}

Virginia Commonwealth University, 2012

Major Director: Christine Reid, Ph.D., Professor, Department of Rehabilitation Counseling

The following is a collection of three separate articles each utilizing a subset of the Integrated Mission System (IMS) of the U.S. Equal Economic Opportunity Commission (EEOC), which includes all Americans with Disability Act (ADA) Title I. cases of workplace discrimination claims files from July 27, 1992 to December 31, 2008. This is a total of 402, 291 claims. Information from the IMS contains indications of how the cases were resolved and not merely statistics at the level of the allegations. This enables research to ascertain the scope of workplace discrimination against people with disabilities. Numerous studies have been done on specific disability groups, but heretofore, no study has placed its primary focus on the "alternate prongs" of the ADA's definition of disability, that is, historical ("record of") and perceived ("regarded as"). Information about these sub-groups highlights the cultural force of stigma as 
well as the propensity to engage in unconscious, automatic judgments, which, while they may be free of animus, still can have deleterious consequences for the workers affected by them. 


\section{Chapter 1}

\section{Defining Disability}

There are three prongs to the definition of "disability" stated in the Americans with Disabilities Act (ADA) of 1990: documented, or "actual"; historical, or "record of"; and perceived, or "regarded as disabled" (U.S. Department of Justice, 2009). This dissertation emphasizes the third prong, although there is some conceptual overlap with the second. In general, both of these prongs involve a perception of disability, thus the inclusion of historical disability within that concept. This arguably indicates a social construction: "People may be 'disabled' under these prongs based upon society's previous observations and perceptions of them." (Eichhorn, 1999, p.1412)

A semantic clarification: some claimants may be considered "disabled" under the second and third prongs, yet they are arguing against an employer's contention that they are "actually" disabled (first prong), when they only have a record of previous disability (with perhaps some minor residua) or a minor impairment that the employer has, consciously or not, amplified to the level of a "true" disability. The law, then, is considering them "disabled" by virtue of societal

myths and stereotyping. (Reisman, 2005, p.2122; Pendo, 2003, p.232) Noting the similarity between these two prongs, Bagenstos (2000) wrote that "A person with a 'record of' an impairment that amounts to a 'disability' remains an individual with a disability for the 
purposes of the statute even after all of the medical effects of the impairment have disappeared." (p.407)

Case law. An example from case law of this conceptual overlap can be found in the landmark ruling of School Board of Nassau County v. Arline (1987) in which a schoolteacher was perceived as disabled based partially on a record of disability (tuberculosis) and terminated. The Arline case separated the issue of contagion from that of impairment, and greatly influenced legal thinking about HIV+/AIDS. According to the Supreme Court deciding on Arline, specific criteria concerning contagion would have to be met to make a case for a public health hazard; otherwise, the claimants in such efforts would be, as Justice William Brennan declared in the majority opinion, "vulnerable to discrimination on the basis of mythology."

When some employers consider an applicant or employee with "a record", there is a conscious or unconscious prejudice activated against the worker (Travis, 2002). Complicating this is the semantics of the term, "record": must it apply only to a tangible document or can it also apply to verifiable history as stated in court? Adding to the ambiguity is the fact that although the 2008 ADA Amendments Act states that reasonable accommodations are not to be given to those perceived as disabled (third prong), thus quashing an ongoing legal debate and rendering much scholarship dated, nothing is said about this issue in relation to the second prong.

The case of Taylor v. Pathmark (1999), illustrating the "pure" third prong issue, was a broad interpretation of perceived disability, dealing with exaggeration of mild impairment, conflicting doctors' notes and the failure of the employer to maintain the requisite interactive process. The claimant, who suffered a leg injury at work, was not sufficiently impaired that he could not return to the job in some capacity, but the employer saw fit to fire him on the mistaken 
notion that the former was "disabled." The key point of the case is that even though employers make an "innocent mistake" in their assessment of a worker with an impairment, they are still subject to liability under the ADA for it. This case ties in with the theory of social cognition/causal attribution and the application of stereotype-driven, unexamined, erroneous heuristics (Tversky and Kahneman, 1974).

By contrast, a narrow interpretation of the ADA's "regarded as" definition is exemplified by Wooten v. Farmland Food (1995). The Appeals Court wrote in this case that "the evidence bearing on the employer's perception of the employee's impairment indicated that its perception was not based upon speculation, stereotype, or myth, but upon a doctor's written restriction of the employee's physical abilities." Another example of restrictive interpretation of the third prong is Rondon v. Wal-Mart, involving a pharmacist with a minor back injury who was terminated and filed a third prong grievance, but lost. The claimant stated that despite the requisite individual assessment of his condition, the employer mistakenly considered him to be disabled, but the court held that this mistake was not covered by the law because back strains are not typically a matter of myth or stereotype. (Travis, 2002). This issue of "innocent mistakes" ties in with theories of causal attribution and implicit bias, discussed below. What is considered misguided in these decisions is the assumption that employers are always rational actors who "absent discriminatory animus, make even-handed decisions using optimal inferential strategies" (Krieger, 1995, p. 1167).

\section{Theoretical Considerations}

Stigma theory. Evidence of negative attitudes toward people with disabilities goes back at least as far as the ancient Greek and Roman practice of infanticide for those born with the 
appearance of disability (Rubin and Roessler, 2008). Although attitudes toward disability have evolved over time, there is still evidence that people with disabilities are stigmatized and experience discrimination (Antonak and Livneh, 2000; Au and Man, 2006). Contemporary stigma theory is usually traced back to the work of Erving Goffman, who defined stigma as "the phenomenon whereby an individual with an attribute is deeply discredited by ...society [and] is rejected as a result of the attribute." Normal identity is "spoiled" by the reactions of others. (Goffman, 1963, p.3). Scambler (2009) argued that Goffman's conceptualization was too limited to the individual/symbolic interactionist level and that stigma should also be analyzed in terms of social macro-structure and political economy. Thorncroft, Rose, Kassam, and Sartorius (2008) criticized the bulk of previous stigma research for a failure to focus on discrimination and human rights. "Instead of asking an employer whether he or she would hire a person with mental illness," they wrote, "we should assess whether he actually does (p.193)."

Link and Phelan (2001) emphasize labeling, status loss, and power differential. They stress the role of stigma in the emergence (or not) of life chances, that is, the opportunities to realize one's potential, in given individuals. For stigma to be reduced, interventions must be chosen which change either attitudes or circumstances of power relations. Beyond legal mechanisms, control over media images would likely play a part. Courtwright (2009) criticized Link and Phelan for not adequately characterizing the phenomenon, stating that it is not merely a matter of discrimination or prejudice but a demand that the object of the treatment share the judgment. Thus, he claimed that internalization is the key feature of the concept. Moreover, it is likely that even those perceived as disabled suffer some emotional consequences from such perception, apart from those secondary to financial loss. Regarding this last point, it is relevant to 
note that internalization is especially acute in the context of poverty, which carries its own stigma, and there is significant indigence among people with disabilities (Rulli and Leckerman, 2005). Recently, Canadian researchers have focused on this aspect, noting a propensity toward internalization of negative attitudes toward indigent individuals, which process can lead to demoralization and depression (Reutter, Stewart, Veenstra, Love, Raphael, and Makwarimba, 2009). There is a paucity of research into the relationship of poverty and disability, one of the reasons being a lack of SES data in the EEOC database and elsewhere. The study of stigma and disability is incomplete without consideration of the relevant social stratification and its psychological effects.

A distinction should be noted between "stigma" and an observable difference in performing "essential job functions." The designation of stigma applies only in situations where the impairment is not a barrier to proper job performance. For example, a runway model with a limp provides an employer with a legitimate argument against employment (at least temporarily), whereas a runway model with a stutter would be experiencing stigma if denied work because of it. Skillful gait is a fundamental of this particular job; skillful speech is not. It would be discriminatory and stigmatizing of those with speech impediments to refuse to hire the latter model on the basis of a quality which is not essential to that job (EEOC, 2005).

Implicit bias. It has been stated in the legal literature that implicit bias against people with disabilities is one of the strongest such biases in American society (Larson, 2008). The social psychological dynamics demonstrated in implicit bias studies are related to the problems of those regarded as disabled, because employers in these cases are often making workplace decisions without being conscious of how they are doing it. Arguing for the relevance of causal 
attribution theory in the disability context, Travis (2002) has described the automatic and often unconscious quality of such attributions. The judging person is not motivated by conscious, emotional prejudice (“animus"), but is making decisions automatically and unconsciously, guided by rules of thumb ("heuristics") informed by stereotypical assumptions about the behavior of a given group of people, in this case, people with disabilities. This goes against the grain of a central assumption of that "queen of social science", economics (or at least the classical version of the discipline), namely, that individuals are rational actors who "maximize utility". However, it was shown by political scientist Herbert Simon (Leahey, 2003) that people do not have perfect knowledge about their opportunities, including those in a workplace situation. There is not only limited information but also a limited capacity to process the information that is available. Thus, instead of rationally optimizing outcomes, choices are often made in the context of uncertainty, of cognitive constraints as well as tendentious social ties. Managerial decision-making frequently occurs, as mentioned above, unconsciously, in an atmosphere of bias that is, as often as not, of a non-invidious nature: emotionality is not an issue in these instances. Simon's theory of bounded rationality influenced the work of Daniel Kahneman, who with Amos Tversky, developed the contemporary conceptualization of heuristics.

Evidence for implicit psychological phenomena in general is considerable (Kihlstron, 1987; Epstein, 1994; Shevrin, 1996; Westen, 1999; Bargh and Williams, 2006). Arguably, the best known work in this area, Harvard's Project Implicit, has received a considerable amount of publicity in recent years for its tests of unconscious social group preferences, the Implicit Association Test (IAT) (Greenwald and Krieger, 2006). In a follow-up study using the IAT, it 
was shown that only age surpassed disability as the basis for the most prominent implicit bias (Larson, 2008).

Causal attribution theory. A division of the field of social cognition, causal attribution theory emphasizes the aforementioned unconscious judgments. These can often be seen as exemplifying the "fundamental attribution error," which refers to the misattribution of behavior to dispositional characteristics of the individual rather than to the situation (Ross, 1977). Moreover, this usually involves certain "heuristics," or mental shortcuts for decision-making, which have been discussed in the disability context (Travis, 2002; Larson, 2008). First, there is the "faulty representation": that any level of impairment is interpreted as indicative of disability. (Tversky and Kahneman, 1974). The prospect of a more realistic, nuanced spectrum of impairment is not considered. Second is the "availability heuristic," an error of facile recall; ongoing observation of the impaired employee tends to amplify the impairment's severity in the employer's mind (Travis, 2002).

In general, consideration of such faulty perception is important because of the effects of discrimination on the individual even when that person doesn't have a disability, as well as implications for people with actual disabilities: the "perceptual effect" exacerbates the social injustice of the "actual" one. (That is, as an aggregate effect, it increases the overall "social presence" of disability discrimination.)

While attribution theory has been criticized (Sabini et al., 2001) as overemphasizing the situation at the expense of a consideration of individual traits, it remains an effective theory for explaining unconscious discrimination against people with disabilities. The "calculations" an employer would have to make to deal with the worker on an individualized basis would be too 
time-consuming, thus it is more convenient to resort to a short-cut which in this context involves accessing stereotypes. The tendency toward "dispositionism" is especially salient when the object of attention is associated with a stigmatized minority. Again, the assumption is that the situations are such that the impairments are not a barrier to proper job performance.

\section{General Considerations}

ADA Amendments Act. The ADA Amendments Act of 2008 is generally considered an attempt to correct overly restrictive interpretation of the original act by the Supreme Court and some lower courts, which led to excessive burden of proof being placed on those filing claims of workplace discrimination due to disability (Long, 2008). For the purposes of this study, the key changes to be noted are a focus on discriminatory actions taken by the employers, rather than a consideration of their mindset (i.e, whether they actually perceived a disability) and making nonmandatory the provision of reasonable accommodations for those workers filing solely on the basis of the third prong (U.S. Access Board, 2009). While generally agreeing that the Amendments Act is a move in the right direction, several legal scholars have criticized some of the language therein as possibly providing an opportunity for more restrictive interpretations of the law. For example, Ara (2010) cited failure of the Act to change the wording of the third prong's definition as possibly causing difficulties for claimants. "The battle over the interpretation of the ADAAA," she wrote, "is just beginning" (p.264). Larson (2008) wrote that in order to reduce implicit bias, the Act should have incorporated broader affirmative action programs, and that there is still sufficient ambiguity in its language to permit narrow interpretations of perceived disability based on implicit bias (p.466). 
Description of the database. The national EEOC ADA research project utilized records extracted from a "master database" of over two million charges in the Integrated Mission System (IMS) of the EEOC. This database includes all ADA-related discrimination complaints filed from the initial implementation of the ADA through the date the data were submitted to researchers in 2009. Within the database, each allegation was the unit of study; confidentiality was protected through purging of data. Only allegations related to ADA Title I. employment provisions were included. Allegations filed on the basis of other employment statutes which vary by jurisdiction were excluded. Only closed allegations from the study period July, 1992, through December, 2008, were included. Allegations still under investigation were excluded from analyses.

The second chapter of this dissertation provides an overview of workplace discrimination and the perception of disability, that is, the "regarded as disabled" ADA definitional prong. The third chapter examines the second prong, namely, the historical or "record of disability." There are relatively fewer claims for this, and it is somewhat neglected in the legal scholarship. The fourth chapter returns to the third prong, but this time considering the interaction of certain variables using a decision tree data mining method, the Chi-Square Automatic Interaction Detector (CHAID). All of the studies employ SPSS standard Chi-Square analysis of age, race, and gender of claimants; size of company; industry type involved; census region where claims were filed; prominent discriminatory issues; and how the cases were resolved, that is, with merit (in favor of the claimant) or without merit (in favor of the employer). 


\section{Significance of the Dissertation}

The aim of this dissertation is to show the characteristics of the perceived and historical disability claimants and the employer-defendants in order to see to what extent discrimination has occurred against this group as compared to the documented disabled group. The third study adds greater depth to the first by examining the possible interactions of predictor variables as they influence the merit outcomes of the cases.

Delimitations. Only cases that were resolved, i.e., closed, by the EEOC were included. (In cases of settlements and mediation, it cannot be known for certain if discrimination occurred.) Only Title I cases are part of the study, and charges of retaliation are not included. The unit of study is a single charge, not a single claimant (who is able to make more than one charge.) The time period is limited from 1992 to 2008 . For the protection of confidentiality of all parties, only the four broad U.S. Census Bureau regions (Northeast, South, Midwest, and West) are used. For the same reasons, the only variables used are charges, case resolutions, claimant's age, race, and gender, defendant's industry type and size, and region of charge's origin.

The following are some basic terms used in this research: EEOC (U.S. Equal Employment Opportunity Commission) is the federal agency which enforces laws making it illegal to discriminate against a job applicant on the basis of disability as well as other basic characteristics, such as race, gender, age, and so on. Title I of the ADA is that portion of the bill which prohibits employers from discriminating against qualified applicants on the basis of disability. IMS (Integrated Mission System) refers to the EEOC's database which contains information about the ADA Title I. violations as well as other laws, such as the Civil Rights Act of 1991. National EEOC/ADA Research Project refers to an informal network discrimination 
and disability going back to 1992 . They have published over 40 articles on the subject in peerreviewed journals. Merit versus Non-merit Resolution refers to outcomes of EEOC investigations of claims of workplace discrimination on the basis of disability. Merit resolutions refer to a conclusion that discrimination did occur or that a settlement/mediation in favor of the charging party was effected (US EEOC, 2003).

Participants. Charges/allegation of workplace discrimination based on perceived disability are the units of study, not the individual claimant; a claimant can make more than one allegation.

There are 40 types of charge variables (i.e., issues). The general categories are job obtainment or membership (e.g., hiring, training); job conditions or circumstances (e.g., demotion, harassment, intimidation, wages); job maintenance or preservation (e.g., discharge, layoff, reinstatement); other/miscellaneous (U.S. EEOC, 2003).

As noted earlier, as of the last update in December 2008, the number of perceived disability claims was over 34,000, and the number of historical disability claims, over 12,000. This is the entire population of such claims as of the last update. The population is easily accessible via SPSS and will be used in lieu of a sample. By contrast, there are over 338,000 allegations for documented disabilities (McMahon et al., 2008). The criterion for inclusion is a formal claim of workplace discrimination based on perceived disability that has been deemed valid by the EEOC. Criteria for exclusion are charges made on the state level, charges of retribution from the employer, and charges still under investigation (McMahon, Edwards, Rumrill, \& Hursch, 2005). 


\section{Data Collection and Proposed Analysis}

Data were collected by the EEOC. A portion of the Integrated Mission System (IMS) database was made available to the Principal Investigator (PI) of the project (B.T. McMahon). A copy of this was obtained on flash drive by the current researcher. Data were collected between 1992 and 2008, but the process continues for the project. Collection took place in every state, in foreign territories and from American expatriates.

The data were reported in grid form of the IMS database with the variables listed above and an ID for each allegation accessible by SPSS. Because data are secondary, generated by a government agency, their validity and reliability have to be assumed. Descriptive analyses (frequencies, percentages, rankings and averages) have been utilized in order to ascertain the most prevalent qualities of claimant characteristics (age, race, gender), employer characteristics (industry and size), regions, charges of discrimination and case resolution. Comparative analysis of perceived and documented disability claims was done using non-parametric (Chi-Square) tests. The rationale for using Chi-Square in the bivariate data is that the nature of the variables is categorical. Age range is rendered dichotomous (below age 50 and 50+). A classification or, decision-, tree analysis (Chi-Square Automatic Interaction Detector, or CHAID) is used for the multivariate data. The rationale for this is that predictor variables can thereby be tested to investigate possible interactions as they impact merit outcome. CHAID, which can complement standard Chi-Square, analyzes, e.g., workplace issues like hiring, firing, harassment, etc., industry type, the region where the claims was filed, etc. and sees what specific which sub-issues make an impact on resolution outcome (McMahon et al., 2008). 
Limitations. Generalizability, usually an issue in studies, is not one here since the entire population of interest is available for analysis. Regarding the unit of study, due to confidentiality, charges cannot be associated with any particular person. As for data accuracy, again, due to the secondary nature of the source, the researcher can only assume that the database was accurately received and recorded by the EEOC. Finally, concerning methodological constraint of variable type, variables are all nominal -age was dichotomized - which eliminates use of parametric tests and limits the range of the research questions.

\section{Paper I: Workplace Discrimination and the Perception of Disability}

This article focuses on claims of workplace discrimination filed with the EEOC on the basis of perceived disability. The following questions are investigated: How do the demographic characteristics of those filing claims for perceived disability differ from those filing claims for documented disabilities? What are the differences between the two groups in terms of industry type, company size, regional location, and worker complaint ("Issue")? Finally, how was each case resolved: with merit (in favor of the worker) or without merit (in favor of the employer)?

\section{Paper II: Workplace Discrimination and the Record of Disability}

This article documents the employment discrimination experienced by Americans with a record of disability, but no current disability, using the Integrated Mission System of the EEOC. Workplace discrimination claims based on historical disabilities are compared and contrasted to those based on current disabilities. Variables examined are age, race, and gender; size of company; region where claim was filed; basis of complaint (Issue); industry type; and outcome of case. 


\section{Paper III: Perceived Disability Claims: A Classification Tree Analysis}

This article builds on the first one, but goes into greater methodological depth by using the classification tree analysis of CHAID to answer the research question: What factors are associated with merit outcomes for people making ADA EEOC complaints who are "regarded as" having disabilities?

\section{Purpose of the Study}

The purpose of this dissertation is to examine the differences between perceived or historical and documented disability claims of workplace discrimination, using information from the database

of the U.S. Equal Employment Opportunity Commission. While numerous articles have been written by legal scholars on perceived disability, this is the first work on the subject to utilize the EEOC database. Variables to be analyzed are age, race, and gender; company size; region where claim was filed; type of charge ("issue"); industry type; and outcome (merit vs. non-merit resolution).

A significant difference in the rate of merit outcomes, adjudged by the EEOC between the two types of disability claims would either support or fail to support the predictors of the theory of causal attribution, which stresses the prominence of implicit bias against given groups in American society. 


\title{
Chapter 2
}

\section{WORKPLACE DISCRIMINATION AND THE PERCEPTION OF DISABILITY}

\author{
By \\ William R. Draper \\ Christine A. Reid \\ Brian T. McMahon
}

\begin{abstract}
This article documents the employment discrimination experienced by Americans "regarded as" disabled (but not medically verified as such), utilizing the Integrated Mission System of the Equal Employment Opportunity Commission (EEOC). Decisions by the EEOC (or a court) in favor of claimants perceived to have disabilities disproportionately exceeded those in favor of claimants with documented disabilities. This finding lends support to the assertion that unconscious/implicit bias is persistent in the workplace.
\end{abstract}




\section{Workplace Discrimination and the Perception of Disability}

In 1990, the U.S. Congress passed the Americans with Disabilities Act (ADA), a landmark piece of legislation which prohibits discrimination against qualified individuals with disabilities (McMahon, Edwards, Rumrill, and Hursch, 2005). The main focus in the workplace discrimination literature has been on documented disabilities, but the ADA has two other definitional categories, or "prongs," namely, "Record of" (referring to those who have a record of having a disability in the past) and "Regarded as" (referring to those who have been perceived as disabled by employers). The ADA Amendments Act of 2008 revised the law so that "it no longer requires showing that the employer perceived the individual to be substantially limited in a major life activity, and instead said that an applicant or employee is 'regarded as' disabled if he or she is subject to an action prohibited by the ADA (e.g., failure to hire or termination) based on an impairment that is not transitory and minor." [Emphasis added] (Larson, 2008). Earlier, a sort of "Catch-22" situation prevailed, in which employees lost their jobs due to being considered disabled, but usually could not get justice in the courts, which considered them not disabled since they were seen as "generally" functional and thus employable elsewhere. This was summed up by Arlene B. Mayerson, an attorney at the Disability Rights Education and Defense Fund (DREDF) as follows: "Hence, an employer may refuse to hire or fire someone because of their disability, and actually defeat coverage by showing that other employers have less discriminatory job requirements. Substitute any other protected group to the analysis and the absurd result is patently clear. We don't hire Jews, but all our competitors do..." (Mayerson, n.d.). Cases of discrimination against individuals regarded as disabled may demonstrate automatic stereotyping of employees and applicants. However, this is not always a conscious, deliberate process. 


\section{Perceived disabilities: Theoretical considerations}

Evidence of negative attitudes toward people with disabilities has a long history, exemplified by the ancient Greek and Roman practice of infanticide for those born with the appearance of disability (Rubin and Roessler, 2008). Although attitudes toward disability have evolved over time, there is still evidence that people with disabilities are stigmatized and experience discrimination (Antonak and Livneh, 2000; Au and Man, 2006). While stigma theory can explain the conscious prejudice against groups or individuals labeled deviant in some fashion (Goffman, 1963; Link and Phelan, 2001), causal attribution theory can explain unconscious bias in the causes assigned to the conduct of another person (Hewstone, 1989; Travis, 2002). (Strictly speaking though, there is theoretical overlap, since automatic, unconscious prejudice assumes the existence of stigma to begin with.) Attempts among the general populace to avoid dysfunctional information overload from a highly complex, technological society have led to increasing reliance on cognitive "shortcuts." Instead of thinking through a situation requiring a judgment, snap decisions are made based on what comes immediately to mind. These rules of thumb, or heuristics, while generally efficient sometimes result in perceptual errors

Contemporary stigma theory is usually traced back to the work of Goffman, who defined stigma as "the phenomenon whereby an individual with an attribute is deeply discredited by ... society [and] is rejected as a result of the attribute. [It] is a process by which the reaction of others spoils normal identity"(Goffman, 1963, p. 3). Scambler (2009) recommended that stigma should also be analyzed more broadly in terms of social macro-structure and political economy.

In the same spirit of conceptual integration, Pescosolido, Martin, Long, and Olafsdottir (2008) proposed that different levels of social life are involved in the process of stigmatization 
including micro (psychological and sociocultural factors at the individual level), meso (social network or organizational factors), and macro (society-wide factors). Thorncroft, Rose, Kassam, and Sartorius (2008) criticized the bulk of previous stigma research for a failure to focus on discrimination and human rights. "Instead of asking an employer whether he or she would hire a person with mental illness, we should assess whether he or she actually does" (p.193). Some Dutch researchers (Heijnders and van der Meij, 2006) have argued that multilevel interventions show the most promise for reducing health-related stigma and discrimination, stating "Reviewed studies showed that a combination of counseling, education and contact are very promising"(p.361).

Link and Phelan (2001) wrote that "stigma exists when elements of labeling, stereotyping, separating, status loss, and discrimination co-occur in a power situation that allows these processes to unfold"(p.364). They stress the role of stigma in the emergence (or not) of life chances, that is, the opportunities to realize one's potential, in given individuals. For stigma to be reduced, interventions must be chosen which change either attitudes or the circumstances of power relations. Beyond legal mechanisms, control over media images would likely play a part.

A distinction should be noted here between "stigma" and an observable difference in performing "essential job functions". The designation of stigma applies only in situations where the impairment is not a barrier to proper job performance. For example, a runway model with a limp provides an employer with a legitimate argument against employment (at least temporarily), whereas a runway model with a stutter would be experiencing stigma if denied work because of it. Skillful gait is a fundamental of this particular job; skillful speech is not. It would be 
discriminatory and stigmatizing of those with speech impediments to refuse to hire the latter model on the basis of a quality which is not essential to that job. (EEOC, 2005)

Naturally, stigma complicates the search for a job. Is it wise for applicants with disabilities to disclose them to potential employers? The literature on such disclosure is sparse, but from it a picture of reluctance emerges. In the area of epilepsy, for example, recent research suggests human resource professionals and employers do not recommend disclosure of that disability in a cover letter (Bishop, Stenhoff, Bradley, and Allen, 2007). Research from psychiatric rehabilitation stresses the importance of disability identity (applicant self-image) and appropriate job matching, stating that "disclosure to an employer was not an acceptable idea for most of the participants [people self-identified as having psychiatric labels] because of their concern about negative response"(Dalgin and Gilbride, 2003, p.308). One personal account of a worker with HIV, whose disclosure turned out to have benign consequences, notes, however, that it is a complex and very individualized situation that requires careful thought. "In some cases," he wrote, "it may actually cause more stress to let people know of your situation, which can adversely affect your health as well." (McMahon, 2003)

It has been stated in the legal literature that implicit bias against people with disabilities is one of the strongest in American society (Larson, 2008). This is one of the conclusions from Harvard's Project Implicit, which has received a considerable amount of publicity in recent years for its controversial test of unconscious social group preferences, the Implicit Association Test (IAT). (Differential response times taken to react to psychologically significant words and images are supposed to indicate prejudice, with the data suggesting, for example, that most people have a slight preference for their own race, although critics argue that the test merely 
reflects familiarity). Evidence for implicit psychological phenomena in general is considerable (Kihlstrom, 1987; Epstein, 1994; Shevrin, 1996; Westen, 1999; Bargh and Williams, 2006). (The last two authors cited elaborated on the notion of "social automaticity", an unconscious automatic stereotyping of those who deviate even slightly from an idea of anatomical or functional "normality.") As the creators of the IAT observed, "Unlike the Freudian revolution...the new science of unconscious mental processes is not the product of a single brilliant theoretical mind. Rather, it is being constructed from an evolving, accumulating body of reproducible research findings" (Greenwald and Krieger, 2006). But if the IAT is a valid measure, as legal scholars in a recent symposium on law and psychology have noted, "Implicit bias poses a special challenge for antidiscrimination law because it suggests the possibility that people are treating others differently even when they are unaware that they are doing so" (Jolls and Sunstein, 2006). A legal commentator has recently noted, in reference to a follow-up study on the IAT, that "disability bias had the second weakest correlation between implicit and explicit attitudes, meaning that people are particularly unwilling to admit - or more likely, are unaware of - their implicit bias against individuals with disabilities... Only attitudes based on age...showed more implicit bias than attitudes toward those with disabilities" (Larson, 2008, p.463).

The social psychological dynamics demonstrated in the implicit bias studies are related to the problems of those regarded as disabled, because employers in these cases are often making workplace decisions without being conscious of how they are doing it.

Several other researchers have linked perceived disabilities and social cognition. How do people explain social events and essentially "peg" others? Arguing for the relevance of causal 
attribution theory in the disability context, Travis (2002) described the automatic and often unconscious quality of such attributions. “... [P] erceived disabilities indeed may result from nonmotivational mistakes...[They] can have purely cognitive origins, independent from invidious prejudice or other forms of group-based decisionmaking, and...these types of errors may be a fairly common event" (pp.491-2). In other words, the judging person is not motivated by conscious, emotional prejudice, but is making decisions automatically and unconsciously, guided by rules of thumb informed by stereotypical assumptions about the behavior of a given group of people, in this case, people with disabilities. As mentioned above, the key notion in social cognition studies is the concept of "information overload". In order to function efficiently in a highly complex world, individuals unconsciously sort, screen, and filter environmental data. "Consider," as one commentator on employment discrimination law and social perception has put it, "all of the information about others that you could absorb in a day as you walk down the street, read newspapers, magazines and books, glance at the mail, watch television, and interact with friends." (Brown, Subrin, \& Baumann, 1997, p.1503). Stereotyping can be seen as just one of the many cognitive strategies the human brain has developed to cope with the plethora of information (Brown, et al., 1997).

To compound the obstacle of discrimination against those who have verified disabilities, there exists discrimination based on mere perception that a person has a disability. (Larson, 2008). An hypothesis to test in future research would involve the possibility of this coming from the employer's mental exaggeration of minor impairment into a disability stereotype. There are two heuristics, or mental shortcuts for decision-making, which have been discussed in the disability context (Travis, 2002; Larson, 2008).. First, there is the "faulty representation": that 
any level of impairment is interpreted as indicative of disability. The prospect of a more realistic, nuanced spectrum of impairment is not considered (Kahneman and Tversky, 1974). Second, is the "availability heuristic", an error of facile recall; ongoing observation of the impaired employee tends to amplify the impairment's severity in the employer's mind. (Travis, 2002).

The concept of an "impairment spectrum," that is, a continuum of severity for impairment, will be proposed as part of an intervention to discourage employers from relying on deleterious, automatically generated stereotypes when making decisions about persons with disabilities.

Before examining the data on the discrimination experience of people perceived to have disabilities, and in order to provide proper context for the present study, it is important to recognize the discrimination experienced by people with documented disabilities. Looking at the overall issue of disability and workplace discrimination as studied by this research project using data from the U.S. Equal Employment Opportunity Commission (EEOC), one sees that many articles have been written in recent years, covering numerous diagnoses, including cancer (McKenna, Fabian, Hurley, McMahon, and West, 2007), traumatic brain injury (McMahon, West, Shaw, Waid-Ebbs, and Belongia, 2005), disfigurement (Tartaglia, McMahon, West, and Belongia, 2005), HIV/AIDS (Conyers, Boomer, and McMahon, 2005), hearing impairment (Bowe, McMahon, Chang, and Louvi, 2005), and autism (Van Wieren, Reid and McMahon, 2008). In general, only one in five of these cases has resulted in a resolution favorable for the charging party. 


\section{The national EEOC ADA research project}

This study utilized records extracted from a "master database" of over two million allegations in the Integrated Mission System (IMS) of the EEOC. This database includes all ADA-related discrimination complaints filed from July 26, 1992 through December 31, 2008. Within the database, each allegation was the unit of study; confidentiality was protected through purging of personal identifiers for both charging parties and employers. Only allegations related to ADA Title I. employment provisions were included. Allegations filed on the basis of other employment statutes which vary by jurisdiction were excluded. Only closed allegations from the study period were included. Allegations still under investigation were excluded from analyses.

The database for the study includes 338,861 allegations made by people who claim to have documented disabilities (DOCDIS) as defined by the first prong of the ADA; 34,222 allegations made by people who claimed to have perceived disabilities (REGAS) as defined by the "regarded as disabled" prong of the ADA.

\section{Research Questions about the "Regarded As Disabled" Prong}

There is a knowledge deficit concerning employment discrimination against individuals perceived to be disabled (as contrasted with those who are documented as having disabilities). Generally, the purpose of this study is to determine if there is a statistically significant difference between characteristics of claims filed on the basis of these two categories. Specifically, the essential research questions are:

(i) What are the demographic characteristics of the Charging Parties, i.e., the individuals filing EEOC allegations? 
(ii) What are the characteristics of the Respondents, i.e., the employers involved? Items include industry designation, size, and regional location.

(ii)What are the Issues, i.e, the nature of discrimination alleged to occur? These refer to objectionable actions by employers.

(iv) How were the cases resolved: with merit (favoring the Charging Party) or without merit (favoring the Respondent)? ("Merit resolution" thus simply refers to the winning of a case by an employee making a claim against an employer.)

\section{Methods}

\section{Analysis}

This is a retrospective quantitative design. Information was not available as to which disabilities were perceived, that is, they were not coded as such. Following a presentation of descriptive statistics, proportion computations were made for the variables of allegation and merit resolution employing SPSS 17.0 (Statistical Package for the Social Sciences). The same program was used for other comparisons between allegations of discrimination against people with documented disabilities ("DOCDIS") and allegations of discrimination against people regarded as having disabilities ("REGAS").

\section{Results}

\section{Findings regarding allegations}

The Integrated Mission System database of the EEOC does not provide information about specific perceived disabilities; they are all coded as one. The overwhelming majority of REGAS 
(perceived disability) cases, about four-fifths, were resolved in favor of the employer. Following are the characteristics of the Charging Parties (CPs) and the Respondents (Rs) on discrimination issues, and findings pertaining to resolutions.

\section{Characteristics of Charging Parties}

The first research question asks about demographic characteristics of the Charging Parties. A typical employee charging workplace discrimination on the basis of perceived disability is a male aged 50 or younger. Compared to male claimants in DOCDIS, there were proportionately fewer Whites, but proportionately more Hispanics, filing claims for REGAS. There is a statistical difference between claims for REGAS over DOCDIS, with REGAS having a greater proportion of discrimination regarding sex (male) as well as a greater proportion for age $\operatorname{group}(>=\mathbf{5 0})$ :

$[\operatorname{Sex}] X^{2}(2, \mathrm{~N}=377580)=190.129 ; \mathrm{p}<0.001 ;$ Cohen's $d=0.04 ;$ and age $(<=50): \mathrm{X}^{2}(1$, $\mathrm{N}=377580)=49.172 ; \mathrm{pp}<0.001 ; d=0.09 ;[$ Age $] \mathrm{X}^{2}(2,377580)=49.17 ; \mathrm{df}=1 . \mathrm{p}<0.001 . \mathrm{d}=$ .09. (See Table 1 for demographic information (i.e, age, sex and race of workers filing discrimination claims).)

\section{Characteristics of Respondents}

The second research question asks about company size, type, and regional location. Although proportionately more DOCDIS claimants in larger companies (500+) filed (41.7\% vs. 39.8\%), there was a significant difference favoring REGAS claimants in smaller (15-100) companies $\left(32.8 \%\right.$ vs.30.9\%): $X^{2}(6, \mathrm{~N}=377580)=158.83 ; \mathrm{p}<0.001$. (See Table 2 for information on company size.) 
As for regional differences, they are proportionately greater for DOCDIS claimants in all regions but the South (REGAS, 33.9\% vs. DOCDIS, 33.6\%): $X^{2}(6, \mathrm{~N}=377580)=3076.583 ; \mathrm{p}<0.001$. (See Table 3 for information on regional distribution of companies.)

For industry types (NAICS), there were also significantly significant differences, with the REGAS claimants proportionately higher in Transportation, followed by Manufacturing and then Construction: $X^{2}(100, \mathrm{~N}=377580)=1237.029 ; \mathrm{p}<0.001$. (The chi square value for the type of industry incorporates data from all Industry types in the North American Industry Classification System (NAICS) of EEOC, not just the selected items in the table. See Table 4 for information on industry type.)

\section{Discrimination Issues}

The third research question asks about the nature of the discrimination alleged to occur, i.e., the "Issues". There were also statistically significant differences in the Issues, with REGAS claims being proportionately higher than DOCDIS regarding Discharge ("involuntary termination of employment status on a permanent basis"), followed by Hiring ("failure by an employer to engage a person as an employer"), then Reinstatement ("failure of an employer to reinstate a person as an employee"). DOCDIS was proportionately higher in Reasonable Accommodations ("Respondent fail[ure] to provide reasonable accommodation to known physical/mental limitations of qualified person with a disability”), followed by Harassment (“antagonism in non-employment situations or settings"), then Discipline ("assessment of disciplinary action against an employee"). (McMahon, Edwards, Rumrill, and Hursch, 2005). $X^{2}(41, \mathrm{~N}=377580=5216.792) ; \mathrm{p}<0.001$. (See Table 5 for information on workplace issues.) 


\section{Findings regarding Resolutions}

The fourth research question asks about how the cases were resolved. Here again, there were differences: Merit resolutions for REGAS proportionately exceeded those for DOCDIS by a statistically significant margin $(26.2 \%$ vs. $22.5 \%): X^{2}(13, \mathrm{~N}=377580=637.383) ; \mathrm{p}<$ $0.001 ; d=.08$. These results reflect the theoretical dynamics of both stigma and causal attribution, since an employer who discriminates against a worker on the basis of perceived disability is, it is argued, being unconsciously motivated by a prejudice against any perception of impairment, regardless of its severity.

Merit resolutions comprise the following four categories: (M1) Withdrawn with benefits by Charging Party (CP), that is, the employee or applicant filing the discrimination claim; (M2) Settled with benefits to CP (where EEOC was party to settlement; (M4) Successful conciliation (EEOC has determined discrimination occurred and Respondent (employer) accepted solution); (M5) Conciliation failure (EEOC has determined discrimination occurred, but Respondent has not accepted resolution).

The largest effect sizes $(d)$ for the variables under study are: 0.23 for Issue, 0.18 for census region (CENREG), 0.12 for Race, and 0.11 for industry type (NAICS). (See Table 6 for information on case resolutions.)

\section{Discussion}

Our research shows that part of discrimination is clearly stigma-based, rather than associated with any differences in reality. This is seen most clearly in the finding regarding case resolutions: again, the merit resolutions for REGAS proportionately exceeded those for DOCDIS 
by a statistically significant margin of $3.7 \%$ (i.e., $26.2 \%$ for the former vs. $22.5 \%$ for the latter). This speaks to an ongoing need for the overcoming of stereotypes. It can, to use a phrase in Goffman's stigma theory, "spoil normal identity" to judge a person with a minor impairment as disabled and perpetrate discrimination in the workplace on that basis (Goffman, 1963). Such stigmatic labeling reduces the life chances of the worker in question by reducing him or her to putatively dysfunctional and nonproductive, second-class status (Link and Phelan, 2001). Causal attribution theory explains the greater percentage of merit resolutions for REGAS by positing a widespread tendency in this society to make automatic, unconscious judgments, judgments which are often erroneous because they are based on simplistic assumptions (Hewstone, 1989).

In the descriptive statistics, one contrast that may be of practical significance is how proportionately fewer Caucasians/Whites filed perceived disability claims, compared to Whites in the DOCDIS group. This information could contribute to the education of employers, suggesting to them that racial or ethnic biases may be unconsciously influencing their decisions to label some employees disabled, who are, in fact, not so. Regarding ageism vs. disability discrimination: interactions were not evaluated. It is possible that variable interactions have confounded results. Further results, possibly using a decision tree program like CHAID (Chi Squared Automatic Interaction Detection) needs to be employed for such interaction determination.

Regarding company size, the somewhat larger proportion of perceived discrimination claims filed in relatively smaller companies (15-100 workers) may reflect more stereotypical thinking toward people with disabilities than in larger companies $(500+$ workers $)(d=0.04)$. But this is only speculative and requires further research for clarification. 
Regional differences between the dataset claims exist and are proportionately greater for documented disabilities (DOCDIS) except for a slightly greater proportion for perceived disabilities (REGAS) in the South $(d=0.18)$. However, the difference in the regions is not sufficiently substantial to justify speculation as to its cause(s).

The higher proportion of claims for REGAS in the Transportation and Manufacturing sectors suggests that employers in these industries should be among those chosen for an intervention. Concerns for traffic safety and efficiency in Transportation and acceptable productivity in Manufacturing should be addressed in the context of the concept of an "impairment spectrum." (For example, is an even morbidly obese truck driver or applicant for that position necessarily unfit to handle the demands of the job (Travis, 2002)? Thinking in the more nuanced terms of a spectrum may encourage a check on prejudicial automaticity, as some social psychologists might term it (Bargh \& Williams, 2006). However, it could also be argued that the increased number of REGAS claims in those industries could be based on the more physically demanding nature of the work, at least in some of the cases.

As for discrimination Issues, REGAS allegations were proportionately higher than those in DOCDIS for Discharge (a 4.7\% difference), followed by Hiring (4.5\%). Why would certain employers be more likely to fire and less likely to hire a worker with an "unreal" disability than a worker with an actual, documented one? How relevant is the prominence of the Transportation and Construction industries in REGAS merit resolutions here? All these findings bring up questions as to their causes, and all are areas that deserve further research.

Since documented disabilities are known and often obvious, one would expect merit resolution rates to reflect this; that is, it is counterintuitive for those with "merely" perceived 
disabilities to have a higher rate of merit closures, yet the data lead to this unexpected conclusion. (With documented disabilities, there is no question that a disability exists, but with perceived disabilities, there is room for doubt.) Merit resolutions for REGAS exceeded those for DOCDIS by a significant margin $(26.2 \%$ vs. $22.5 \%)$. This finding lends support to the claim that implicit bias is pervasive in the workplace, just as it is American society in general (Larson, 2008; Greenwald and Krieger, 2006).

Calculations of effect size herein have yielded rather low levels, but critics should not be quick to jump to dismissive conclusions. As Rosenthal (1990) has noted, it is important to put the numbers in the context of real-life cases. "When we think of an $r$ of .04 as reflecting a 4\% decrease in heart attacks...the $r$ does not appear to be quite so small, especially if we can count ourselves among the 4 per 100 who manage to survive" (p.775). Likewise, in the context of impairment-related workplace discrimination, losing one's job is serious, especially with the stigma of disability attached to it. Difficult economic times exacerbate the problem. In an analysis of hiring discrimination, McMahon et al. (2008) opined that "small differences in proportion may have substantial impact. Each discriminatory event is an insidious violation of civil rights with serious psychological, financial, career, and integrity consequences to all parties concerned" (p.110). While these authors argue that the small effect size is not so insignificant after all when the impact on the lives of the affected individuals is considered, it could also be argued that, in the aggregate, one is still looking at an accepted indicator (i.e., Cohen's $d$ ) of a slight overall practical significance.

Among the strategies that have proposed for changing stigma are protest, education and contact. Protest is thought to be most effective when the media are the target of change; likewise, 
education, though perhaps less effective, may help foster change through public service announcements. Contact is thought to show the most promise, but it is probably more successful when its scope is limited. (Corrigan and Wassel, 2008). Further research would be needed to determine whether and how such methods may or may not apply in cases of implicit bias.

To help remedy workplace discrimination against those perceived as disabled, an intervention for employers is proposed. Although unconscious processes cannot directly be engaged in this context, the problem can be confronted obliquely. First, the decision-makers should be persuaded that such automatic, inferential errors are indeed occurring. "Applying the perceived disability prong to nonmotivational [i.e., unconscious and unintentional] mistakes," wrote Travis (2002), "would be the first step in getting employers to recognize this propensity...[then]...they must take conscious, proactive steps to improve the accuracy of their inferential judgments.'(p.508) Travis explained that research in cognitive bias suggests the best way to reduce the fundamental attribution error of blaming the person rather than the situation is to force employers to take the perspective of the employee and to focus on the situational factors constraining the latter's actions. A reduction in bias may result if employers are required to make a case contrary to their intended one. Furthermore, legal mandates to engage the employee interactively in the evaluative process are congruent with research on cognitive accuracy. An oftcited example is Barnett vs. US Air, Inc. (2000); the opinion expressed by that court emphasized that the interactive process is vital to the ADA's process.

"As part of the interactive process, employers should first analyze the purpose and essential function of the job involved. Next, the employer should consult with the...employee, obtaining as much information as possible about the individual's...limitations. In this 
consultation, both...should discuss available alternatives." (Wheeler, 1999, p.889) In the context of perceived disability, the interactive process should focus on the efficacy of the applicant/employer, that is, his/her ability to perform the given tasks despite a presumed perception of serious limitations. Naturally, how the ADA Amendments Act of 2008 will be interpreted remains to be seen, but "by returning the focus of claims brought under the ADA to the discriminatory actions by the employer rather than the employer's subjective mindset," wrote Larson (2008, p.463), “courts are more likely to account for situations where implicit bias results in discriminatory behavior without intent on the part of the employers."

This intervention should involve the idea of an "impairment spectrum," which simply refers to a continuum of severity for injuries and disorders and is the conceptual framework the employer could use in place of the unrealistic and pernicious, black-and-white stereotype of "the disabled" vs. "the normal". That is to say, when an employer fails to take into account the nuances and details of a particular case of impairment, such as that of an employee whose leg was injured on the job, and makes a one-size-fits-all decision of "disability" without taking into account what the worker can still do, that employer is engaging in simplistic, stereotyped thinking rather than in a more complex, realistic consideration of the particular case at hand. Many examples and scenarios could be used for this (some from actual court cases). Employers have exaggerated the significance of tics, disfigurements, injuries, asthma, epilepsy, carpal tunnel syndrome, obesity, dysthymia, high blood pressure, and so on (Travis, 2002).

One relevant example here is that of Taylor vs. Pathmark Stores (1999). An employer fired a worker with a minor injury, but the latter was able to file a perceived disability claim based on the fact that despite the employer's presumably innocent mistake, he still had the 
responsibility to properly evaluate the worker to make sure the gravity of the injury was not exaggerated.

In terms of implications for rehabilitation, a counseling intervention might involve teaching clients to be proactive and pre-empt employer prejudgment using evidence-based selfadvocacy statements, usually linked to a well-constructed resume. For example, applicants or employees-at-risk could say, "Let me assure you, I can do all this..." or "You may have a concern about my ability here, but let me tell you how I handled this before..." What is being proposed here are counteracting statements, those that “de-bias" or counter employers' faulty assumptions about the worker, who should ask him/herself, "How can I identify what he's thinking about me and how to dispel it?" With conditions that are not obvious, research suggests disclosure could be counterproductive (Bishop et al., 2007) (Dalgin and Gilbride, 2003); in these cases, the focus should be on a self-empowering interpretation of the employee/applicant's behavior. Thus, anticipating negative prejudgment and providing evidence-driven alternate explanations for behavior that would serve a de-biasing purpose could be at the heart of an effective counseling intervention with this population.

\section{Conclusion}

Not only does the conscious social psychological factor of stigma come into play in workplace discrimination, but so does implicit bias, that is, unconscious stereotyping by the employer. Analysis of EEOC data demonstrates that mere perception of disability constitutes a significant aspect of workplace discrimination against workers with non-disabling impairments (and perhaps, with none at all). Recommended are interventions that emphasize not only the problem of stigma, but also that of automatic cognitive biases with a focus on an impairment 
spectrum. The use of such a concept may help correct simplistic and inaccurate employer perceptions which are damaging to workers with non-disabling impairments and, by extension, to the population of people with documented disabilities as well. 


\section{References}

Antonak, R.F. \& Livneh, H. (2000) Measurement of attitudes towards persons with disabilities. Disability and Behavior, 22,(5), 211-224.

Au, K.W. \& Man, D.W.K. (2006) Attitudes toward people with disabilities: a comparison between health care professionals and students. International Journal of Rehabilitation Research, 29(2), 155-160.

Bargh, J.A., \& Williams, E.L. (2006). The automaticity of social life. Current Directions in Psychological Science, 15, 1-4.

Barnett v. U.S. Air, Inc. (2000). U.S. Circuit Court of Appeals, 228 F. 3d. 1105.

Bishop, M., Stenhoff, D.M., Bradley, K.D., \& Allen, C.A. (2007) The differential effect of epilepsy labels on employer perceptions: Report of a pilot study. Epilepsy and Behavior $11,351-356$.

Bowe, F.G., McMahon, B.T., Chang, T. \& Louvi, I. (2005) Workplace discrimination, deafness and hearing impairment: the national EEOC ADA research project. Work, 25 (1), 19-25.

Brown, J.O., Subrin, S.N., \& Baumann, P.T. (1997). Some thoughts about social perception and employment discrimination law: A modest proposal for reopening the judicial dialogue. Emory Law Journal, 46, 1487. 
Conyers, L., Boomer, K.B. \& McMahon, B.T. (2005) Workplace discrimination and HIV/AIDS: the national EEOC ADA research project. Work, 25, (1), 37-48.

Corrigan, P.W. \& A. Wassel (2008). Understanding and influencing the stigma of mental illness. Journal of Psychosocial Nursing, 46, 42-48.

Dalgin, R.S. \& Gilbride, D. (2003) Perspectives of people with psychiatric disabilities on employment disclosure. Psychiatric Rehabilitation Journa,l, 26 (3), 306-310.

Epstein, S. (1994). Integration of the cognitive and the psychodynamic unconscious. American Psychologist, 49, 709-724.

Goffman, E. (1963). Stigma: Notes on the management of spoiled identity. Englewood Cliffs, NJ: Prentice-Hall.

Greenwald, A.G., \& Krieger, L.H. (2006). Symposium on behavioral realism: Implicit bias: Scientific foundations. California Law Review, 94, 943.

Heijnder, M. \& van der Meij, S. (2006). The fight against stigma: An overview of stigmareduction strategies and interventions. Psychology, Health, \& Medicine, 11, 353-363.

Hewstone, M. (1989). Causal attribution: From cognitive processes to collective beliefs. Oxford, UK: Blackwell.

Huber, L.P., \& Johnson, R.N., \& Kohli, R. (2006). Naming racism: A conceptual look at internalized racism in U.S. schools. Chicano-Latino Law Review, 26, 183.

Jolls, C., \& Sunstein, C.R. (2006). Symposium on behavioral realism: The law of implicit bias. California Law Review, 94, 969. 
Kihlstrom, J.F. (1987). The cognitive unconscious. Science(Sept. 18) 237, 1445.

Larson, D. (2008). Unconsciously regarded as disabled: Implicit bias and the Regarded-As prong of the ADA. UCLA Law Review, 56, 451.

Link, B.G., \& Phelan, J.C. (2001). Conceptualizing stigma. Annual Review of Sociolog,y 27, 363-385.

Mayerson, A.B. (no date). Too disabled or not disabled enough? Disability Rights Education \& Defense Fund. http://www.dredf.org/publications/mayerson_2.html

McKenna, M.A., Fabian, E., Hurley, J.E., McMahon, B.T., \& West, S.L. (2007) Workplace discrimination and cancer. Work, 29 (4), 313-322.

McMahon, B.T., Edwards, R., Rumrill, P.D., \& Hursh, N. (2005). An overview of the national EEOC ADA research project. Work, 25, 1-7.

McMahon, B.T., Hurley, J.E., West, S.L., Chan, F., Roessler, R, Rumrill, P.D., Jr. (2008). A comparison of EEOC closures involving hiring versus other prevalent discrimination issues under the Americans with Disabilities Act. Journal of Occupational Rehabilitation, 18, 106-111.

McMahon, B.T., West, S.L., Shaw, L.R., Waid-Ebbs, K., \& Belongia, L. (2005) Workplace discrimination and traumatic brain injury: the national EEOC ADA research project. Work, 25(1), 67-75.

McMahon, S. (2003 Sept/Oct) Disclosing HIV in the workplace: One personal perspective from the corporate world. http://www.thebody.com/content/art30528.html 
Accessed 10/23/09.

National Poverty Center, University of Michigan (2008). Poverty in the United States: Frequently asked questions. http://www.npc.umich.edu/poverty/ Accessed 9/24/09.

Pescosolido, B.A., Martin, J.K., Long, A., \& Olafsdottir, S. (2008). Rethinking theoretical approaches to stigma: A framework integrating normative influences on stigma (FINIS). Social Science \& Medicine, 67, 431-440.

Reutter, L.I., Stewart, M.J., Veenstra, G., Love, R., Raphael, D., \& Makwarimba, E. (2009). "Who do they think we are, anyway?": Perceptions of and responses to poverty stigma. Qualitative Health Research, 19, 297-311.

Ritsher, J.B., Otilingma, P.G., \& Grajales, M. (2003). Internalized stigma of mental illness: Psychometric properties of a new measure. Psychiatry Research, 121, 31-49.

Ross, M.W., \& Rossen, B.R.S. (1996). Measurement and correlates of internalized homophobia: A factor analytic study. Journal of Clinical Psychology, 52, 15-21.

Rosenthal, R. (1990). How are we doing in soft psychology? American Psychologist, 45, 776777.

Rowen, C.J., \& Malcolm, J.P. (2002). Correlates of internalized homophobia and homosexual identity formation in a sample of gay men. Journal. of Homosexuality, 43, 77.

Rubin, S.E. \& Roessler, R.T. (2008) Foundations of the vocational rehabilitation process. $6^{\text {th }}$ ed. Austin, TX: Pro-ed. 
Rulli, L.S. \& Leckerman, J.A. (2005). Unfinished business: The fading promise of ADA enforcement in the Federal courts under Title I. and its impact on the poor. Journal of Gender, Race, and Justice, 8, 595.

Rutter, M. (2006). Implications of resilience concepts for scientific understanding. Annals of the New York Academy of Sciences, 1094, 1-12.

Scambler, G. (2009). Health-related stigma. Sociology of Health \& Illness, 31, 441-455.

Shevrin, H. (1996). Conscious and unconscious processes: Psychodynamic, cognitive and neurophysiological convergences. New York: Guilford Press.

SPSS. (2008). SPSS 17.0 for Windows, release 17.0.0. Chicago: Author.

Tartaglia, A., McMahon, B.T., West, S.L., \& Belongia, L. (2005) Workplace discrimination and disfigurement: the national EEOC ADA research project. Work 25(1), 57-65.

Taylor v. Pathmark Stores, Inc. (1999). U.S. Court of Appeals, 177 F. 3d. 180.

Thornicroft, G., Rose, D., Kassam, A., \& Sartorius, N. (2007). Stigma: Ignorance, prejudice, or discrimination? British Journal of Psychiatry, 190, 192-193.

Travis, M.A. (2002). Perceived disabilities, social cognition, and "innocent mistakes". Vanderbilt Law Review, 55, 481.

Tversky, A. \& Kahneman, D. (1974). Judgment under uncertainty: Heuristics and biases. Science 27 Sept.;185(4157), 1124-1131. 
U.S. Equal Employment Opportunity Commission (EEOC) (2005). The ADA: Your employment rights as an individual with a disability.

http://www.eeoc.gov/facts/ada18.html.

Accessed 5/15/10.

U.S. Equal Employment Opportunity Commission (2009). Notice concerning the ADA Amendments Act of 2008.

http://www.eeoc.gov/ada/amendments_notice.html.

Accessed 7/2/09.

Van Wieren, T.A., Reid, C.A., \& McMahon, B.T. (2008) Workplace discrimination and autism spectrum disorders: the national EEOC ADA research project. Work, 31(3), 299-308.

Vauth, R., Kleim, B., Wirtz, M., \& Corrigan, P.W. (2007). Self-efficacy and empowerment as outcomes of self-stigmatizing and coping in schizophrenia. Psychiatry Research, 150, 7180.

Westen, D. (1999). The scientific status of unconscious processes: Is Freud really dead? Journal of the American Psychoanalytic Association, 47,1061-1106.

Wheeler, C.M. (1999). Comment. Employment-Barnett v. U.S. Air, Inc.: The interactive process and the ADA. University of Memphis Law Review, 29, 883. 
Table 1

Characteristics of Charging Parties

\section{REGAS}

Frequency Percentage

Gender

Male

Female

Age

$<50$

$\geq 50$

Ethnicity

Asian

AfricAm

Hisp

Mixdethn

NativAm

White

Other

Unknwn*
20637

17723

24612

11352

436

6582

2265

6

199

19878

2304

7049
$53.3 \%$

$45.8 \%$

$68.4 \%$

$31.6 \%$

$1.1 \%$

$17.0 \%$

$5.8 \%$

$0.0 \%$

$0.5 \%$

$51.3 \%$

$6.0 \%$

$18.2 \%$
DOCDIS

Frequency Percentage

$173416 \quad 51.2 \%$

$163733 \quad 48.3 \%$

$213188 \quad 70.2 \%$

$90384 \quad 29.8 \%$
$3496 \quad 1.0 \%$

$61435 \quad 18.1 \%$

$18425 \quad 5.4 \%$

$203 \quad 0.1 \%$

$1990 \quad 0.6 \%$

$188952 \quad 55.8 \%$

$25201 \quad 7.4 \%$

$39142 \quad 11.6 \%$

Note: AfricAm = African American Hisp = Hispanic/Mexican; Mixdethn = Mixed race; NativAm = Native American/Alaskan Native; Unknwn = 4 "null" categories merged. REGAS = Regarded as disabled/perceived disability cases; DOCDIS $=$ Documented/ "actual" disability cases; Gender: $\mathrm{p}<0.001$; effect size (Cohen's d) $=0.04$; Age: $\mathrm{p}<0.001$; $\mathrm{d}=0.09$; Ethnicity: $\mathrm{p}<$ $0.001 ; \mathrm{d}=0.128$. 
Table 2

Number of Employees

\begin{tabular}{lllllll}
\hline & $\underline{15-100}$ & $\underline{101-200}$ & $\underline{201-500}$ & $\underline{500+}$ & $\underline{\text { Other }}$ & $\underline{\text { Unknown }}$ \\
REGAS & 12710 & 4368 & 4326 & 15407 & 1593 & 287 \\
& $32.8 \%$ & $11.3 \%$ & $11.2 \%$ & $39.8 \%$ & $4.1 \%$ & $0.7 \%$ \\
& & & & & & \\
DOCDIS & 104841 & 38131 & 35623 & 141196 & 16868 & 1886 \\
& $30.9 \%$ & $11.3 \%$ & $10.5 \%$ & $41.7 \%$ & $5.0 \%$ & $0.6 \%$ \\
\hline
\end{tabular}

Note: $\mathrm{p}<0.001$; Effect size (Cohen's $d)=0.04$. 
Table 3

Geographical region.

\begin{tabular}{llllll}
\hline & Northeast & Midwest & South & West & Other \\
REGAS & 2643 & 6831 & 13132 & 5541 & 77 \\
& $6.8 \%$ & $17.6 \%$ & $33.9 \%$ & $14.3 \%$ & $0.2 \%$ \\
& & & & & \\
DOCDIS & 32135 & 84497 & 113824 & 49979 & 1168 \\
& $9.5 \%$ & $24.9 \%$ & $33.6 \%$ & $14.7 \%$ & $0.3 \%$ \\
\hline
\end{tabular}

Note: Northeast $=$ Connecticut, Maine, Massachusetts, New Hampshire, Rhode Island, Vermont, New Jersey, New York, Pennsylvania. Midwest = Indiana, Illinois, Michigan Ohio, Wisconsin, Iowa, Kansas, Minnesota, Missouri, Nebraska, North Dakota, South Dakota. South = Delaware, District of Columbia, Florida, Georgia, Maryland, North Carolina, South Carolina, Virginia, West Virginia, Alabama, Kentucky, Texas, Mississippi, Tennessee, Arkansas, Louisiana, Oklahoma. West = Arizona, Colorado, Idaho, New Mexico, Montana, Utah, Nevada, Wyoming, Alaska, California, Hawaii, Oregon, Washington. Other = US territories and foreign countries. $p$ $<0.001$; effect size $(d)$ for region variable $=0.18$. 
Table 4

NAICS (Industry type)

\begin{tabular}{llllll} 
& Mining & Construction & Manufacturing & Wholesale & Retail \\
REGAS & 299 & 2917 & 6949 & 758 & 2786 \\
& $0.7 \%$ & $\mathbf{2 . 5 \%}$ & $\mathbf{1 7 . 4 \%}$ & $1.9 \%$ & $7.2 \%$ \\
DOCDIS & 2346 & 5899 & 55175 & 5890 & 26415 \\
& $0.7 \%$ & $\mathbf{1 . 8 \%}$ & $\mathbf{1 6 . 5 \%}$ & $1.8 \%$ & $7.8 \%$ \\
& Transport. & Information & Finance/Real & Health & Public \\
& & & Estate & Care & Admin. \\
& 2276 & 1206 & 1975 & 4130 & 7436 \\
REGAS & $\mathbf{5 . 8 \%}$ & $3.0 \%$ & $4.2 \%$ & $10.7 \%$ & $8.2 \%$ \\
& 15568 & 12523 & 16603 & 36626 & 30659 \\
DOCDIS & $\mathbf{4 . 5 \%}$ & $4.0 \%$ & $4.9 \%$ & $10.8 \%$ & $8.9 \%$ \\
& & & & & \\
\hline
\end{tabular}

Note: Top ten categories by numerical $(\%)$ value. NAICS $=$ North American Industrial Classification System. The Chi-Square value (1237.09) refers to the total NAICS Industry type data, not just the selected items in the table; $\mathrm{p}<0.001$; Cohen's $\mathrm{d}=0.11$. 
Table 5

Issues

\section{REGAS higher}

\section{REGAS}

DOCDIS

$\begin{array}{lllll}\text { Discharge } & 14282 & 36.9 \% & 109025 & 32.2 \% \\ \text { Hiring } & 3601 & 9.3 \% & 16326 & 4.8 \% \\ \text { Reinstatement } & 887 & 2.3 \% & 4571 & 1.3 \% \\ \text { Terms/Conditions } & 3684 & 9.5 \% & 29078 & 8.6 \% \\ \text { Prohibited Medical } & 487 & 1.3 \% & 1877 & 0.6 \% \\ \text { Inquiry } & & 1.9 \% & & \\ \text { Assignment } & 719 & & 4454 & 1.3 \%\end{array}$

DOCDIS higher

DOCDIS REGAS

\begin{tabular}{lcccc} 
Reasonable & 65758 & $19.4 \%$ & 3161 & $8.2 \%$ \\
Accommodations & & $7.9 \%$ & 2507 & $6.5 \%$ \\
Harassment & 26669 & $3.7 \%$ & 1174 & $3.0 \%$ \\
Discipline & 12670 & $2.5 \%$ & 800 & $2.1 \%$ \\
$\begin{array}{l}\text { Constructive } \\
\text { Discharge }\end{array}$ & 8341 & $1.3 \%$ & & \\
Benefits & 4335 & & 344 & $0.9 \%$ \\
& & & & \\
\hline
\end{tabular}

Note: $\mathrm{p}<0.001$; Cohen's $\mathrm{d}=0.23$. 
Table 6

Resolutions

Merit resolutions

10,152

$26.2 \%$

75,732

$22.5 \%$
Not merit resolutions

28,567

$73.8 \%$

263,129

$77.5 \%$

Note: Merit resolutions, i.e., cases won by the claimant/worker, comprise the following four categories: Withdrawn with benefits by CP (M1); Settled with benefits to CP (where EEOC was party to settlement (M2); Successful conciliation (EEOC has determined discrimination occurred and Respondent accepted solution) (M4); Conciliation failure (EEOC has determined discrimination occurred, but Respondent has not accepted resolution) (M5). Bolded percentages emphasize that there were proportionately more "wins" for claimants in perceived disability cases than in documented disability cases. $\quad \mathrm{p}<0.001$; Cohen's $\mathrm{d}=0.08$. 


\title{
Chapter 3
}

\section{WORKPLACE DISCRIMINATION AND THE RECORD OF DISABILITY}

\author{
By \\ William Draper \\ Carolyn Hawley \\ Brian T. McMahon \\ Christine A. Reid
}

\begin{abstract}
This article documents the employment discrimination experienced by Americans with a record of disability but no current disability, utilizing the Integrated Mission System of the Equal Employment Opportunity Commission (EEOC). Decisions by the EEOC in favor of charging parties with historical disabilities disproportionately exceeded those in favor of charging parties
\end{abstract}


with current disabilities. This finding suggests that discrimination against persons who have only a record of disability persists in the workplace, and that this additional aspect of the definition of the term "disability" is viable.

\section{Workplace Discrimination and the Record of Disability}

Recently, the U.S. Congress passed the Americans with Disabilities Act Amendments Act of 2008 (ADAAA), which was drafted to correct restrictive interpretations of the 1990 Americans with Disabilities Act (ADA) by the Supreme Court. There are three prongs to the definition of "disability" in both acts: actual, historical (record of a disability), and perceived (regarded as disabled). Although the amendments will make it easier for aggrieved parties to file allegations for actual or perceived disability discrimination, it is unclear how the 2008 update will affect allegations related to historical disabilities (Long, 2008).

\section{Theoretical Background}

Although attitudes toward disability have evolved over time, there is still evidence that people with disabilities are stigmatized and experience discrimination (Antonak \& Livneh, 2000; Au \& Man, 2006). This can be true for actual, perceived, or historical disabilities. For example, in the historical case, there appears to be an attitude of "once crazy, always crazy". It appears that in many instances, a once excellent worker is viewed with skepticism following an injury or accident with even minor limitations. When some employers consider an applicant or employee with a record of having a disability, there can be a conscious or unconscious prejudice activated against the worker (Travis, 2002). 
Contemporary stigma theory may shed some light on this problem. It is traced back to the work of Goffman (1963), who characterized stigma as the spoilage of normal identity by social reactions which discredit the individual because of an attribute which others find unacceptable. Link and Phelan (2001) argued that the stigmatizing effects of labeling and discrimination taking place in a power situation reduce opportunities for the stigmatized person. While stigma theory (the "spoiling of normal identity" by group disapproval of an attribute) can explain the conscious prejudice against groups or individuals labeled deviant in some fashion (Goffman, 1963; Link and Phelan, 2001), causal attribution theory can explain unconscious bias in the causes assigned to the conduct of another person (Hewstone, 1989; Travis, 2002).

Causal attribution theory addresses assignment of causes, justified or not, to observed behavior. Travis (2002) described attributions as automatic and often unconscious judgments which are unintentional mistakes. Although these processes allow efficient decision-making in general, the overload of information in contemporary society can result in an unfortunate byproduct. In brief, people attempt to mitigate information overload by relying on cognitive shortcuts and snap judgments. These heuristics, generally efficient rules of thumb, sometimes result in perceptual and cognitive errors. The type of error that may be most relevant to the case of historical disability is that of the representative heuristic (Tversky and Kahneman, 1974). This mistake in judgment occurs when one presumes that another whose attributes superficially resemble those of a given group must be a member of that group. In this case, "once disabled, always disabled" is the rule of thumb.

For example, the stigma of mental illness has been explored theoretically in terms of justification of the status quo (Corrigan, Watson, \& Ottati, 2003). Often people with mental 
illness are stereotyped as dangerous, incompetent and/or in need of institutionalization. As such, the system is correct to intervene, and obsolete and expensive bureaucracies are perpetuated through “deviance making” (Tversky and Kahneman), 1974).

\section{Record of disability and the ADA Amendments}

There have been several prominent and controversial issues related to the historical prong of the definition of disability. These include the utility of its inclusion in the definition, the semantics surrounding what constitutes a "record," and the severity (nature, scope, and duration) of the historical disability. Most of the legal attention surrounding this aspect of the ADA has involved whether or not employers are required to "accommodate" historical disability, and if so, how is this accomplished?

The 2008 Amendments (ADAAA, 2008) cleared some of this confusion. They maintained both alternative prongs (record of and regarded as) and thus confirmed the utility of these definitional features. The Amendments went further and required two important things:

a. Impairments that are episodic or in remission are still a current disability if it would substantially limit a major life activity when active. Examples include epilepsy, PTSD, diabetes, asthma, cancer, and bipolar disorder.

b. there is no minimum duration for an impairment that qualifies it as substantially limiting. It is possible for an impairment which lasts a short period of time to be covered if it is sufficiently severe.

c. the determination of whether an impairment rises to the level of substantial limitation must be made without regard to the ameliorative effects of mitigating measures, which may in- 
clude medication, medical supplies, equipment, appliances, low-vision devices, prosthetics, hearing aids, cochlear implants, mobility devices, oxygen therapy equipment and supplies; the use of assistive technology; reasonable accommodations or auxiliary aids of services; or learned behavior or adaptive neurological modification (examples only).

By specifically strengthening the first prong of the ADA definition of disability in these ways, reliance on the "record of" prong may be less frequent in a world after the amendments. The passage of the amendments reaffirmed the reasonable accommodation question, however, with this language. "An employer is required, absent undue hardship, to provide reasonable accommodation to a qualified individual with a substantially limiting impairment or a 'record of' such an impairment, but is not required to provide a reasonable accommodation to an individual who meets the definition of disability solely under the 'regarded as' prong" (ADAAA, 2008, p2). For example, absent hardship, an employer would have to afford opportunities for follow-up medical appointments to review the current status of a historical disability if consistent with good medical practice.

\section{Research Questions}

The theories of stigma and causal attribution are relevant to each research question in this study. Ageism, racism, and sexism could all amplify the stigma of disability, either consciously or through contribute to implicit bias pertinent to age, race and gender. Regarding employer characteristics, some areas of the country, some industries, and some larger or smaller companies could, for various reasons directly related to a given characteristic, evince more or less conscious stigmatizing behavior and/or implicit bias. Likewise, certain issues by their nature might bring stigma or unconscious prejudice into play. Finally, the matter of actual discrimination, as 
determined by merit closure decisions, is logically either conscious and/or unconscious, and the theories of stigma and causal attribution can account for these respective cognitions/behaviors.

Generally, the purpose of this study is to determine if there are statistically significant differences between characteristics of allegations filed on the basis of documented ("actual") vs. historical disabilities.

Specifically, the essential questions are:

Research Question 1: Do the demographic characteristics of the person claiming discrimination (Charging Party) differ between the two types of allegations, RECDIS (historical disability) and NOWDIS (current disability)?

Research Question 2: Do the employer (Respondent) characteristics (company size, industry size, region where allegations were filed) differ between RECDIS and NOWDIS?

Research Question 3: Are there differences between the Issues (i.e., alleged discriminatory actions of employers) for RECDIS and NOWDIS?

Research Question 4: Is there a difference between the rates of merit resolution between RECDIS and NOWDIS? "Merit resolution" is a determination by the EEOC that discrimination occurred.

The fourth question is the most important, as the outcome reflects whether discrimination did in fact occur. There are four types of merit resolutions: withdrawn with benefit by charging party, settled with benefits to charging party, successful conciliation, and conciliation failure (the last referring to a situation where the EEOC has determined 
discrimination, but the employer has not accepted the resolution). There are ten types of nonmerit resolution, the largest being "no cause finding." The remaining nine non-merit types involve administrative technicalities (e.g., one or both parties cannot be located, employer is bankrupt, EEOC lacks jurisdiction).

\section{Methods}

This study utilized records extracted from a "master database" of over two million allegations in the Integrated Mission System (IMS) of the EEOC. This database includes all ADA-related discrimination complaints filed from July 26, 1992 through December 31, 2008. Within the database each allegation was the unit of study; confidentiality was protected through purging of personal identifiers for both charging parties and employers. Only allegations related to ADA Title I. employment provisions were included. Allegations filed on the basis of other employment statutes which vary by jurisdiction were excluded. Only closed allegations from the study period were included; allegations still under investigation were excluded from analyses.

The database for the study included 338,861 allegations made by people who claim to have documented disabilities (NOWDIS) as defined by the first prong of the ADA and 12,047 allegations made by people with a history of disability (RECDIS) as defined by the "record of disability" prong of the ADA. In the case of alternative prongs, information was not available as to the specific impairment of the Charging Party.

In EEOC parlance, individuals who bring allegations of workplace discrimination are referred to as "charging parties." Employers against whom allegations are filed are referred to as "respondents." At the conclusion of the EEOC investigation, the outcome is recorded as a 
"resolution" which may be either "merit" (favoring charging party) or "non-merit" (favoring respondent).

For the purposes of this research project:

- "Hiring" is defined as failure by an employer to engage a person as an employee;

- "Terms/Conditions" as denial or inequitable application of rules relating to general working conditions or the job environment and employment privileges which cannot be reduced to monetary value;

- "Reinstatement" as failure of an employer to reinstate a person as an employer;

- "Reasonable accommodations" as failure of an employer to provide reasonable accommodation to known physical/mental limitations of qualified person with a disability;

- "Discharge" as involuntary termination of employment status on a permanent basis;

- "Harassment" as antagonism in non-employment situations or settings. (McMahon, Edwards, Rumrill, \& Hursch, 2005)

Analysis. This is a retrospective, non-experimental, quantitative design. Following a presentation of descriptive statistics, Chi Square tests of proportion were carried out using SPSS 17.0 for the variables of charging party characteristics, respondent characteristics, and resolution status. The same program was used for other comparisons between allegations of discrimination against people with current disabilities (NOWDIS) and allegations of discrimination against people with a history of disability (RECDIS). 
To control for Type I error rate arising from multiple Chi-Square analyses, a stringent alpha level of 0.001 was set.

\section{Results}

\section{Characteristics of the Charging Parties}

Demographics of the charging parties are provided in Table 1. There was a significant difference between groups for the variable of gender with $54.0 \%$ of the RECDIS group male vs. $51.4 \%$ of NOWDIS group male. Conversely, females were $48.6 \%$ of NOWDIS and only $46.0 \%$ of RECDIS. $X^{2}=33.20 ; \mathrm{df}=1 ; \mathrm{p}<0.001$; Cohen's $d=0.026$.

As for ethnicity, the greatest difference observed is in the White category $(55.8 \%$ for NOWDIS, $52.9 \%$ for RECDIS). $X^{2}=35.52 ; \mathrm{df}=6 ; \mathrm{p}<0.001 ; d=0.022$. The proportion of nonWhite complaints was larger for the RECDIS category than for the NOWDIS category.

Regarding age, the younger group $(<50)$ filed more claims in both categories. However, the percentage of the young group filing RECDIS was lower than the percentage filing NOWDIS. Conversely, the percentage of the older group filing RECDIS was larger than the percentage filing NOWDIS. $X^{2}=251.77 ; \mathrm{df}=70 ; \mathrm{p}<0.001 ; d=0.056$.

\section{Characteristics of Respondents}

For both RECDIS and NOWDIS categories, allegation levels were highest for large companies with 500+ employees; $44.6 \%$ of RECDIS complaints and $41.7 \%$ of NOWDIS complaints were from such large employers. $X^{2}=64.97 ; \mathrm{df}=3 ; \mathrm{p}<0.001 ; d=0.028$. See Table 2. 
For both the RECDIS and NOWDIS categories, the largest proportion of claims made were in the South (49.3\% for RECDIS and $40.4 \%$ for NOWDIS). Although the proportion of RECDIS claims in the South appears higher than the proportion of NOWDIS claims in the South, the reverse situation applies to the Midwest, where the proportion of NOWDIS claims $(30.0 \%)$ is higher than the proportion of RECDIS claims $(19.2 \%) . X^{2}=614.4 ; \mathrm{df}=5 ; \mathrm{p}<0.092$; $d=0.092$. See Table 3 .

Industry designations confirm to the North American Industry Classification System (NAICS). For industry types, allegation levels were higher for RECDIS industries including Health Care/Social Assistance (11.8\% vs. 10.8\%) and Transportation and Warehousing (5.3\% vs. 4.5\%). Conversely, lower allegation levels existed for RECDIS industries such as Finance/Insurance category (3.3\% vs. $4.2 \%)$, Retail Trades (7.0\% vs. $7.8 \%)$, and Public Administration $(8.1 \%$ vs. $8.9 \%) . X^{2}=663.86 ; \mathrm{df}=101 ; \mathrm{p}<0.001 ; \mathrm{d}=0.096$. See Table 4 .

\section{Discrimination Issues}

Issues involve the unlawful personnel actions alleged to have been perpetrated by the Respondents. Based on percentage differences between the two types of disability, higher allegation levels were detected for RECDIS issues in Hiring (7.6\% vs. 4.8\% for NOWDIS), followed by Terms/Conditions (10.6\% vs. $8.6 \%$ ) and then Reinstatement (2.1\% vs. 1.3\%). The most common allegation was Discharge, but this was more frequent in NOWDIS (32.2\%) than in RECDIS (29.6\%). $X^{2}=834.79 ; \mathrm{df}=41 ; \mathrm{p}>0.001 ; \mathrm{d}=0.098$. See Table 5 .

\section{Findings regarding Resolutions}

Overall merit findings were greater among RECDIS resolutions (25.7\% vs. 22.3\%). 
$X^{2}=87.37 ; \mathrm{df}=1 ; \mathrm{p}>0.001 ; \mathrm{d}=0.032$. See Table 6. Roughly, three-quarters of allegations resulted in non-merit findings by the EEOC. In both RECDIS and NOWDIS groups, the majority of outcomes were non-merit, consistent with previous research regarding discrimination complaints (McMahon \& Hurley, 2008; Chan, McMahon, et al., 2005). Moreover, the proportion of merit outcomes in the RECDIS category is higher than the proportion of merit outcomes in the NOWDIS category. Among the 4 types of merit resolutions and RECDIS allegation levels were higher across the board beginning with "Settled with benefits to the charging party" (10.8\% vs. $8.8 \%$ ) and "Conciliation failure (4.0\% vs. $2.8 \%)$. In this category, the EEOC has determined that sufficient evidence of discriminatory event exists, but the Respondent has not accepted the proposed solution of "remedy for breach." Smaller differences favoring RECDIS allegation levels were found for "Withdrawn with benefits by charging party" and "Successful conciliation" in which the EEOC has made a finding of merit and proposed a solution acceptable to the respondent.

The largest category of non-merit findings involves a "no-cause" determination by the EEOC which is in effect a vindication of the respondent. RECDIS and NOWDIS allegation levels were separated by only $0.3 \%$ proportion. All other non-merit categories involve administrative closures or technicalities such as "Lack of EEOC jurisdiction" which was markedly lower for RECDIS (4.7\% vs. 6.3\%). Lower levels of allegation activity for RECDIS resolutions also occurred for the administrative closures of "non-respondents" and "uncooperative" charging parties. 


\section{Discussion}

The research suggests that discrimination may be based in part upon stigma. It is clear that beyond the existence of a substantially limiting impairment in real time, a record or history of such an impairment also has a discernible effect upon workplace discrimination. This is nowhere more evident than in the significantly elevated merit rate for the RECDIS allegation group.

In the descriptive statistics, by a fairly wide margin, the proportion of allegations filed by RECDIS workers over 50 years of age was proportionately greater than the proportion of allegations filed by NOWDIS workers over 50 years of age. How much of this is a reflection of age bias vs. stigma from past disability is unknown. It is reasonable to conclude that an older worker has more time and opportunity to build a record of impairment than a younger individual.

As for company size, the higher RECDIS allegation levels among larger employers may be due to their propensities to be more likely to provide health insurance coverage, more likely to experience workplace injuries, and more likely to have developed human resource departments capable of examining work and safety matters within the workforce. In brief, more such experience may lead to more opportunities for bias to emerge. On the other hand, more scrutiny could lead to attenuation of stereotyping.

State-level data were unavailable for this study, however, regional differences appear to exist and may be explained in part by the lower levels of unionization in Southern states. For example, North Carolina (3.1\%), South Carolina (4.5\%), Georgia (4.6\%), Virginia (4.7\%), Mississippi (4.8\%), Texas and Tennessee (5.1\%) unionization rates (U.S. Bureau of Labor Statistics, 2010). 
Differences in the allegation levels for RECDIS among employers vary, suggesting that some industries might benefit from a targeted employer education program specific to the "record of disability". Groups such as the ADA National Network or the U.S. Business and Leadership Network could provide meaningful resources for technical assistance. Similarly, ADA-related training regarding "record of disability" may be designed in such a way that the issues of Hiring, Terms/Conditions, and Reinstatement are highlighted. These are the "high risk" personnel actions, from an employer perspective.

On the findings of Merit Resolution, since current disabilities are known and often obvious, one might expect merit resolution rates to reflect this; that is, it is counterintuitive for those with "merely" record-of disabilities to have a higher rate of merit closures. Yet the data lead to this unexpected conclusion. With current disabilities there is no question that a disability exists; however with historical disabilities there is room for doubt. Merit resolutions for RECDIS exceeded those for NOWDIS by a significant margin $(25.7 \%$ vs. $22.3 \% ; d=0.032)$. This finding lends support to the allegation that implicit bias is prevalent in the workplace, just as in American society in general (Larson, 2008; Greenwald and Krieger, 2006).

Recent research in social psychology has shown automatic stereotypes to be malleable (for a review, see Blair (2002); also Stewart \& Payne (2008) for experiments). To help remedy workplace discrimination against those with a record of disability, an intervention for employers is proposed by the present authors. Although unconscious processes cannot be directly engaged in this context, the problem can be confronted obliquely. First, the decision-makers may be introduced to the possibility that such automatic, inferential errors are indeed occurring. Travis (2002) recommended that to reduce the fundamental attribution error of blaming the person 
rather than the situation is to require employers to take the perspective of the employee and to focus on the situational factors constraining the latter's actions. A reduction in bias may result if employers are required to make a case contrary to their intended one.

In terms of implications for rehabilitation intervention might involve teaching clients to be proactive with their employment endeavors. Thus, clients need to anticipate possible criticisms from employers and have ready-made refutations for them based on the evidence of the job record as well as soundly reasoned arguments showing a high degree of competence and preparedness for any contingencies the position may present.

\section{Conclusions}

A "record of" disability allegation may involve stigma and unconscious stereotyping on the part of the employers. Analysis of EEOC data shows that there is a disproportionate, statistically significant higher rate of merit resolution for allegations of historical disability than for current disability. Because there appears to be a propensity for employers to hold these charging parties' "deviant pasts" against them, the second prong has a role to play in countering workplace discrimination. Debiasing interventions may be of value in correcting inaccurate employer perception regarding competence of workers with a record of disability. 


\section{References}

ADA Amendments Act of 2008 (2008). Public Law 110-325.

Antonak, R.F. \& Livneh, H. (2000). Measurement of attitudes towards persons with disabilities. Disability and Behavior, 22(5), 211-221.

Au, K.W. \& Man, D.W.K. (2006). Attitudes toward people with disabilities: A comparison between health care professionals and students. International Journal of Rehabilitation Research, 29(2), 155-160.

Autry, J.R. (2004). Reasonable accommodations under the ADA: Are employers required to participate in the interactive process? The courts say "yes", but the law says "no". Chicago-Kent Law Review, 30, 513.

Chan, F., McMahon, B.T., Cheing, G., Rosenthal, D.A., Bezyad, J. (2005). Drivers of workplace discrimination against people with disabilities: The utility of attribution theory. Work, 25, $77-88$.

Corrigan, P.W., Watson, A.C., \& Ottati, V. (2003). From whence comes mental illness? International Journal of Social Psychiatry, 49 (2), 142-157.

Goffman, E. (1963). Stigma: Notes on the management of spoiled identity. Englewood Cliffs, N.J.: Prentice-Hall.

Hewstone, M. (1989). Causal attribution: From cognitive processes to collective beliefs. Oxford, UK: Blackwell. 
Link, B.G. \& Phelan, J.C. (2001). Conceptualizing stigma. Annual Review of Sociology, 27, 363385.

Long, A.B. (2006). (Whatever happened to) the ADA's "Record of" prong? Washington Law Review, 81, 669.

Long, A.B. (2008). Introducing the new and improved Americans with Disabilities Act: Assessing the ADA Amendments Act of 2008. Northwest University Law Colloquy, 103, 217.

McKenna, M.A., Fabian, E., Hurley, J.E. Hurley, McMahon, B.T., \& West, S.L. (2007). Workplace discrimination and cancer. Work, 29, 313-322.

McMahon, B.T. and Hurley, J.E. (2008). Discrimination in hiring under the Americans with Disabilities Act: An overview of the National EEOC ADA Research Project. Journal of Occupational Rehabilitation, 18, 103-105.

SPSS (2008). SPSS 17.0 for Windows, release 17.0.0. Chicago: Author.

Travis, M.A. (2002). Perceived disabilities, social cognition, and "innocent mistakes." Vanderbilt Law Review, 55, 481.

Tversky, A. and Kahneman, D. (1974). Judgment under uncertainty: Heuristics and biases. Science, 27 September; 185(4157), 1124-1131. 
Table 1

Characteristics of Charging Parties

\begin{tabular}{|c|c|c|c|c|c|}
\hline & \multicolumn{2}{|c|}{ RECDIS } & \multicolumn{2}{|c|}{ NOWDIS } & \multirow[b]{2}{*}{ Significance } \\
\hline & Frequency & Percentage & Frequency & Percentage & \\
\hline Gender & & & & & $\begin{array}{l}X^{2}=33.20 ; \mathrm{df}=1 ; \\
d=0.026\end{array}$ \\
\hline Male & 7341 & $54.0 \%$ & 173416 & $51.4 \%$ & \\
\hline Female & 6265 & $46.0 \%$ & 163733 & $48.6 \%$ & \\
\hline Age & & & & & $\begin{array}{l}X^{2}=251.77 ; \mathrm{df}=70 ; \\
d=0.056\end{array}$ \\
\hline$<50$ & 8559 & $62.2 \%$ & 213188 & $70.2 \%$ & \\
\hline$\geq 50$ & 4180 & $37.8 \%$ & 90384 & $29.8 \%$ & \\
\hline Ethnicity & & & & & $\begin{array}{l}X^{2}=243.27 ; \mathrm{df}=10 ; \\
d=0.052\end{array}$ \\
\hline Asian & 190 & $1.4 \%$ & 3496 & $1.0 \%$ & \\
\hline AfricAm & 2288 & $16.7 \%$ & 61435 & $18.1 \%$ & \\
\hline Hisp & 729 & $5.3 \%$ & 18425 & $5.4 \%$ & \\
\hline Mixethn & 2 & $0.0 \%$ & 203 & $0.1 \%$ & \\
\hline NativAm & 69 & $0.0 \%$ & 1990 & $0.6 \%$ & \\
\hline White & 7254 & $52.9 \%$ & 188952 & $55.8 \%$ & \\
\hline Other & 1049 & $7.6 \%$ & 25201 & $7.4 \%$ & \\
\hline Unknown* & 2142 & $15.6 \%$ & 39142 & $11.6 \%$ & \\
\hline
\end{tabular}

*The Unknown category merges 4 "null" categories. Abbreviations: "AfricAm" = African American; "Hisp" = Hispanic/Mexican; "Mixethn" = Mixed race; "NativAm" = Native American/Alaskan Native. "RECDIS" = Record/history of disability cases; "NOWDIS" = Documented/current disability cases

$* *$ Gender $\mathrm{p}<0.001 ;$ Age $\mathrm{p}<0.001 ;$ Ethnicity $\mathrm{p}<0.001$ 
Table 2

Characteristics of Respondent: Employer size

\begin{tabular}{ccccccc}
\hline \multicolumn{7}{c}{ Number of Employees } \\
\hline & $\mathbf{1 5 - 1 0 0}$ & $\mathbf{1 0 1 - 2 0 0}$ & $\mathbf{2 0 1 - 5 0 0}$ & $\mathbf{5 0 0 +}$ & Other & Unknown \\
\hline RECDIS & & & & & \\
$\mathbf{N}$ & 3854 & 1567 & 1523 & 6119 & 542 & 117 \\
$\%$ & $28.1 \%$ & $11.4 \%$ & $11.1 \%$ & $44.6 \%$ & $4.0 \%$ & $0.9 \%$ \\
NOWDIS & & & & & & \\
N & 104841 & 38131 & 35623 & 141196 & 16868 & 1886 \\
$\%$ & $30.9 \%$ & $11.3 \%$ & $10.5 \%$ & $41.7 \%$ & $5.0 \%$ & $0.6 \%$ \\
\hline
\end{tabular}

$X^{2}=120.10 ;$ df $=6 ; \mathrm{p}<0.001 ; d=0.036$. 
Table 3

Respondent Characteristics: Geographical Region

\begin{tabular}{cccccc}
\hline & Northeast & Midwest & South & West & Other \\
\hline RECDIS & & & & & \\
$N$ & 1194 & 1958 & 5035 & 2012 & 20 \\
$\%$ & $11.7 \%$ & $19.2 \%$ & $49.3 \%$ & $19.7 \%$ & $0.2 \%$ \\
NOWDIS & & & & & \\
$N$ & 32135 & 84497 & 113824 & 49979 & 1168 \\
$\%$ & $11.4 \%$ & $30.0 \%$ & $40.4 \%$ & $17.7 \%$ & $0.4 \%$ \\
\hline
\end{tabular}

$X^{2}=614.40 ; \mathrm{df}=5 ; \mathrm{p}<0.001 ; d=0.092$.

Northeast $=$ Connecticut, Maine, Massachusetts, New Hampshire, Rhode Island, Vermont, New Jersey, New York, Pennsylvania. Midwest = Indiana, Illinois, Michigan, Ohio, Wisconsin, Iowa, Kansas, Minnesota, Missouri, Nebraska, North Dakota, South Dakota. South = Delaware, District of Columbia, Florida, Georgia, Maryland, North Carolina, South Carolina, Virginia, West Virginia, Alabama, Kentucky, Texas, Mississippi, Tennessee, Arkansas, Louisiana, Oklahoma. West = Arizona, Colorado, Idaho, New Mexico, Montana, Utah, Nevada, Wyoming, Alaska, California, Hawaii, Oregon, Washington. Other = US territories and foreign countries. (McMahon et al., 2005) 
Table 4

Employer Industry

\begin{tabular}{llccc}
\hline & \multicolumn{2}{c}{ RECDIS } & \multicolumn{2}{c}{ NOWDIS } \\
\hline INDUSTRY & Frequency & Percentage & Frequency & Percentage \\
\hline Manufacturing & 2335 & $16.9 \%$ & 55,555 & $16.5 \%$ \\
Hlth Care \& Soc Asst & 1620 & $11.8 \%$ & 46,626 & $10.8 \%$ \\
Public Administration & 1143 & $8.1 \%$ & 30,659 & $8.9 \%$ \\
Retail Trade & 936 & $7.0 \%$ & 25,794 & $7.8 \%$ \\
Transport/Warehsng & 710 & $5.3 \%$ & 15,668 & $4.5 \%$ \\
Educational Services & 660 & $4.8 \%$ & 17,678 & $5.2 \%$ \\
Prof/Sci/Tech & 524 & $3.8 \%$ & 11,937 & $3.5 \%$ \\
Information & 511 & $3.5 \%$ & 13,523 & $4.0 \%$ \\
Finance/Insurance & 459 & $3.3 \%$ & 13,752 & $4.2 \%$ \\
Construction & 297 & $2.1 \%$ & 5,839 & $1.8 \%$ \\
\hline
\end{tabular}

Top ten categories for RECDIS by numerical (\%) value.

The Chi-Square figure refers to the total NAICS Industry type data, not just the selected items on the table.

$X^{2}=663.86 ; \mathrm{df}=101 ; \mathrm{p}<0.001 ; d=0.096$. 
Table 5

Discrimination Issues

\begin{tabular}{lcccc}
\hline & \multicolumn{2}{c}{ RECDIS } & \multicolumn{2}{c}{ NOWDIS } \\
\hline & Frequency & Percentage & Frequency & Percentage \\
\hline Discharge & 4061 & $29.6 \%$ & 109025 & $32.2 \%$ \\
Reasonable Accom. & 1997 & $10.6 \%$ & 65758 & $19.4 \%$ \\
Terms/Conditions & 1459 & $10.6 \%$ & 29078 & $8.6 \%$ \\
Hiring & 1046 & $7.6 \%$ & 16326 & $4.8 \%$ \\
Harassment & 947 & $6.9 \%$ & 26669 & $7.9 \%$ \\
Promotion & 338 & $2.5 \%$ & 7061 & $2.1 \%$ \\
Reinstatement & 289 & $2.1 \%$ & 4571 & $1.3 \%$ \\
Constructive Discharge & 287 & $2.1 \%$ & 8341 & $2.5 \%$ \\
Intimidation & 246 & $1.8 \%$ & 4086 & $1.2 \%$ \\
Wages & 222 & $1.6 \%$ & 6640 & $2.0 \%$ \\
\hline
\end{tabular}

Top ten categories for RECDIS by numerical (\%) value.

$X^{2}=834.79 ; \mathrm{df}=41 ; \mathrm{p}<0.001 ; d=0.098$. 
Table 6

Merit \& Non-merit Resolutions

\begin{tabular}{lcccc}
\hline & \multicolumn{2}{c}{ RECDIS } & \multicolumn{2}{c}{ NOWDIS } \\
& $N$ & $\%$ & $N$ & $\%$ \\
& & & & \\
\hline Merit & 3533 & $25.7 \%$ & 10189 & $22.3 \%$ \\
Non-merit & 75732 & $74.3 \%$ & 263129 & $77.7 \%$ \\
& & & & \\
\hline
\end{tabular}

$X^{2}=87.37 ; \mathrm{df}=1 ; \mathrm{p}<0.001 ; d=0.032$.

Merit resolutions comprise the following four categories: Withdrawn with Benefits by CP (M1); Settled with Benefits to CP (where EEOC was party to settlement) (M2); Successful Conciliation (EEOC has determined discrimination occurred and Respondent accepted solution) (M4); Conciliation Failure (EEOC has determined discrimination occurred, but Respondent has not accepted resolution) (M5). 


\title{
Chapter 4
}

\section{ADA PERCEIVED DISABILITY CLAIMS: A CLASSIFICATION TREE ANALYSIS}

\author{
by \\ William R. Draper \\ Carolyn E. Hawley \\ Brian T. McMahon \\ Christine A. Reid
}

\begin{abstract}
The purpose of this study is to examine the possible interactions of predictor variables pertaining to perceived disability claims contained in a large governmental database.

Specifically, it is a retrospective analysis of U.S. Equal Employment Opportunity Commission (EEOC) data for the entire population of workplace discrimination claims based on the "regarded as disabled" prong of the Americans with Disabilities Act (ADA) definition of disability. The study utilized records extracted from

a "master database" of over two million charges of workplace discrimination in the Integrated Mission System (IMS) of the EEOC. This database includes all ADA-related discrimination
\end{abstract}


complaints filed from July 26, 1992 through December 31, 2008. Chi-Squared Automatic

Interaction Detection (CHAID) was employed to analyze interaction effects of relevant variables, such as Issue (grievance) and Industry Type. The research question addressed by CHAID is: What combination of factors are associated with merit outcomes for people making ADA EEOC complaints who are "regarded as" having disabilities? The CHAID analysis shows how merit outcome is predicted by the interaction of relevant variables. Issue was found to be the most prominent variable in determining merit outcome, followed by Industry Type, but the picture is made more complex by qualifications regarding Age and Race data. Although Discharge was the most frequent grievance among claimants in the perceived disability group, its merit outcome was significantly less than that for the factor cluster of Hiring and Suspension.

\section{Introduction to Alternate Prongs}

The Americans With Disabilities Act of 1990 (ADA) states a three-pronged definition of "disability": that which is current and documented; that which is historical ("record of disability"); and that which is perceived ("regarded as disabled"). In the context of workplace discrimination, the latter refers to perceptions of an employer, especially an exaggerated view of an impairment which elevates it to disability status. Such misperceptions can lead to unfair bias in numerous ways: in hiring, discharge, demotion, harassment, and so on.

A previous study of perceived disability discrimination analyzed differences in merit outcome and other variables compared to claims of discrimination on the basis of documented (“actual”) disability (Draper, Reid, and McMahon, 2011). (Merit outcome refers to yes-or-no decisions made by the Equal Employment Opportunity Commission (EEOC) on the validity of worker grievances.) The purpose of the present study is to consider allegations of perceived 
disability discrimination in greater depth by utilizing a decision tree analysis, Chi-Square Automatic Interaction Detector (CHAID), to examine interactions between variables related to merit outcome, for example, specific grievance (Issue) and Industry Type. In doing so, one may gain greater insight into the specific nature of a given allegation: In which industries is it likely to be found? Is it more likely to be filed by a certain members of a certain age group, gender, or racial or ethnic group within those industries? Answers to these more magnified concerns may have implications for intervention by rehabilitation professionals.

Rather than the total absence of an impairment, most cases of regarded-as claims involve an impairment the seriousness of which may be exaggerated in the mind of the employer, such that he/she believes the worker incapable of performing the essential duties of the job at hand. This misperception tends to be unconscious, rather than a calculated act of "animus" against the employee (Travis, 2002). Furthermore, such implicit bias also tends to reflect a societal-wide propensity to commit occasional cognitive errors as a byproduct of using mental shortcuts to cope with the information overload of a highly complex, technological environment (Brown, 1997). These "innocent mistakes" can be seen in the broader context of general unconsciousness of mental processes which, while still a controversial topic in psychology, has gained more acceptance in the past quarter-century due to research in both neuroscience and empirical social psychology (Larsen, 2008). In order to provide a fuller picture of the theoretical background of what has been termed causal attribution theory in the field of social cognition (Hewstone, 1989), some of the key scientific breakthroughs in this area will be reviewed below. 


\section{Theoretical Background}

Stigma theory. Stigma theory can be useful for explaining disability discrimination. Contemporary stigma theory is usually traced back to the work of Goffman, who defined stigma as "the phenomenon whereby an individual with an attribute is deeply discredited by ... society [and] is rejected as a result of the attribute. [It] is a process by which the reaction of others spoils normal identity" (Goffman, 1963, p.3). Scambler (2009) recommended that stigma should also be analyzed more broadly in terms of social macro-structure and political economy. Link and Phelan (2001) stressed the role of stigma in the emergence (or not) of life chances, that is, the opportunities to realize one's potential, in given individuals. For stigma to be reduced, interventions must be chosen which change either attitudes or the circumstances of power relations. Beyond legal mechanisms, control over media images would likely play a part. Courtwright (2009) emphasized that it is not merely a matter of discrimination or prejudice, but a demand that the object of the treatment share the judgment for stigma to have its effect. Thus, he claimed that internalization is the key feature of the concept. Regarding the present study, it is likely that even those perceived as disabled experience emotional consequences from such perception, apart from those secondary to financial loss.

Naturally, stigma complicates the search for a job. Is it wise for applicants with disabilities to disclose them to potential employers? The literature on such disclosure is sparse, but from it a picture of reluctance emerges. In the area of epilepsy, for example, recent research suggests human resource professionals and employers do not recommend disclosure of that disability in a cover letter (Bishop, Stenhoff, Bradley, \& Allen, 2007). Research from psychiatric rehabilitation stresses the importance of disability identity (applicant self-image) and appropriate 
job matching, stating that most people self-identified as having psychiatric labels were loath to disclose such information for fear that it would be poorly received (Dalgin \& Gilbride, 2003). Allegations on the basis of psychiatric disability have been shown to be significantly less likely to be meritorious by the EEOC than those filed on the basis of physical disability (An, Roessler, and McMahon, 2011).

. While the passage of the Americans with Disabilities Amendments Act holds promise for ameliorating the judicial situation for claimants, as Larson (2008) has noted, there are still problems. Ara (2010) echoed this:

By superceding the Sutton decision, the additional definition of perceived disability established a more inclusive standard. Congress broadened groups than can allege discrimination based on perceived disability, but narrowed the remedies available to them. Although Congress intended to provide courts with a clear and enforceable standard, ambiguity remains. By retaining the original definition of disability instead of changing the wording, Congress failed to counteract all of the confusion that the courts struggled with before passing the Amendments. Additionally, the intent of Congress may perplex the courts because it both broadened and restricted the protection for those who are 'regarded as' disabled. Based on these potential problems, courts may still misinterpret congressional intent under the ADAAA (p.256).

\section{Causal attribution theory: Implicit bias and unconscious mental processes}

Causal attribution theory is a variant of general attribution theory which incorporates heuristics. These sometimes inaccurate mental shortcuts in decision-making (Hewstone, 1989) can be used to explain the implicit aspects of disability discrimination (Travis, 2002). The two 
heuristics most relevant to discrimination are likely to be those of representation and availability. Representation refers to the cognitive error of interpreting any level of impairment as indicative of disability (Tversky \& Kahneman, 1974). Availability refers to an error of facile recall; continual observation of the employee tends to amplify the impairment's severity in the employer's mind (Travis, 2002). Such fallacious attributions are made automatically, generally without conscious realization of the thought process involved.

Rudman, Ashmore, and Gary (2001) reported experimental results which show evidence of the malleability of implicit prejudice and stereotypes. Dasgupta and Greenwald (2001) have noted that the teaching of anti-biasing strategies to motivated individuals has shown the plasticity of automatic beliefs. They also report results of their experiments on prejudice using the Implicit Association Test (IAT) which provide evidence for the malleability of automatic intergroup attitudes (Greenwald and Banaji, 1995). Kawakami, Dovidio, Moll, Hermsen, \& Russin (2000) demonstrated experimentally that subjects could be trained to overcome automatic stereotype activation through an extensive training in negating such associations. Blair (2002) reviewed evidence for the malleability of automatic stereotypes and prejudice, noting nearly a decade ago that there were already nearly 50 studies of flexibility and responsiveness to various influences. They concluded that highly motivated individuals can overcome prejudicial automaticity. In the context of the ADA and perceived disability, a desire on the part of employers to avoid possibly costly investigation and litigation from workplace discrimination charges could serve as a substantial basis for motivation to participate in a debiasing program.

One challenge to a psychoeducational intervention that deals with implicit bias is the "underground" affective component of discrimination. Disability professionals must realize that 
sometimes emotion is not secondary to cognition, but is primary (Zajonc, 1980; Shean, 2001). The neurobiological basis of the primacy of affect can totally bypass the cortex by utilizing solely subcortical structures, viz., the thalamus and amygdala. (The cortico-amygdala pathway, which does involve cognition, is considerably slower.) LeDoux's work is a major contribution to the case for implicit affect. Subcortical pathways, he notes, provide the anatomical framework for fear conditioning, and emotional memories formed in these areas tend to be indelible (LeDoux, 1989). However, even LeDoux noted that cognitive behavioral therapy is an effective counseling modality for anxiety disorders, which is encouraging for those attempting an intervention involving affective aspects of unconscious mentation, especially since the implicit bias of workplace discrimination is not as deep-seated a psychological phenomenon as a clinical syndrome.

The area of implicit affect and cognition that is of most relevance to the present study is that of unconscious prejudice. One major development in social psychology, Harvard's Project Implicit, has been an ongoing program based on research into unconscious social cognition as it applies to various forms of social discrimination. The basic instrument used in this work is the Implicit Association Test (IAT). Based on differential response times to paired images and words of significance to the issue, prejudicial feelings about various minority groups have been shown to exist in individuals who consciously disavow them (Greenwald, McGhee, \& Schwartz, 1998) .

Tying together the neurobiological and social-psychological, Phelps, O'Connor, Cunningham, Funayama, Gatenby, Gore, \& Banaji (2000) used functional magnetic resonance imaging (fMRI) with the IAT on White American subjects, investigating their amygdala activity when they were shown Black and White males faces in two separate experiments. They found 
that the responses were indicative of individualized cultural judgments of social groups. Larson (2008) has recently noted, in reference to a follow-up study on the IAT, that only ageism was more pronounced than disability discrimination. "Disability bias had the second weakest correlation between implicit and explicit attitudes, meaning that people are particularly unwilling

to admit - or more likely, are unaware of - their implicit bias against individuals with disabilities" (p.463). More recently, Chen, Ma and Zhang (2011), in a study of Chinese undergraduates taking the IAT, showed that despite the explicit demonstration of positive attitudes toward people with disabilities, negative attitudes were expressed implicitly. Draper, Reid, and McMahon (2011) showed that decisions by the EEOC in favor of claimants perceived to have disabilities disproportionately exceeded those in favor of claimants with documented disabilities. The present study builds on those findings by examining which variables may interact to predict merit outcome.

\section{Methodology}

The present study examines the effects of variables pertaining to perceived disability claims contained in a large governmental database. Specifically, it is a retrospective analysis of EEOC data, but rather than involving a sample, it includes the entire population of claims based on the "regarded as disabled" prong of the ADA definition of disability.

The authors utilized records extracted from a "master database" of over two million charges in the Integrated Mission System (IMS) of the EEOC. This database includes all ADArelated discrimination complaints filed from July 26, 1992 through December 31, 2008. Within the database, each allegation was the unit of study; confidentiality was protected through purging identifying information from the data. Only allegations related to ADA Title I employment 
provisions were included. Allegations filed on the basis of other employment statutes which vary by jurisdiction were excluded. Only closed allegations from the study period July, 1992 through December, 2008 were included. Allegations still under investigation in December 2008 were excluded from analyses.

The database for the study includes 338,861 allegations made by people who claim to have documented disabilities (DOCDIS) as defined by the first prong of the ADA and 34,222 allegations made by people who claimed to have perceived disabilities (REGAS) as defined by the "regarded as disabled" prong of the ADA.

For each case, the following data were available:

- Age of Charging Party (CP): $(\leq 29 ; 30-39 ; 40-49 ; 50-59 ; \geq 60)$.

- Gender of CP

- Race/Ethnicity of CP (Black, Hispanic, White, Asian, Mixed Ethnicity, Other)

- Census Region where complaint was filed (4 main areas: Northeast, South, Midwest, West)

- Size of company (i.e., number employed: 15-100; 100-200; 201-500; 500+)

- Issue (discrimination complaint based on Hiring, Discharge, Demotion, etc.)

- Employer Industry (BLS/NAICS categories: Transportation/Warehousing; Health care/Social Assistance, etc.)

- Outcome of conflict (Merit or Non-merit resolution/closure) 
A decision-tree analysis, i.e., a graphic, tree-like classification model which investigates multi-level interactions, is employed here to "break down" the components of the relevant variables, that is, to analyze the interacting predictor variables which influence the dependent variable of Merit Outcome. Chi Square Automatic Interaction Detection (CHAID) is a nonparametric statistical technique which explores categorical data for possible interactions. With this method, combinations of variables serving as predictors of merit outcome for the cases are tested individually (Chan et al, 2005). The specifics of the method are explained below. The software used was SPSS Answer Tree 3.1.

The research question is: What combination of factors (variables) are associated with merit outcomes for people making ADA EEOC complaints who are "regarded as" having disabilities?

Data analysis. Chi Square Automatic Interaction Detection (CHAID) is a non-parametric exploratory decision-tree technique, i.e., a tree-like model which investigates multilevel interactions, for extracting meaningful patterns of information from large databases. CHAID prioritizes groups of homogeneous allegations, or end groups, on the basis of their contribution to the outcome variable of merit resolution. (McMahon, Hurley; 2008). The end groups are show on the classification tree as "nodes". With this method, combinations of variables serving as predictors of merit outcome for the cases are tested individually (Chan et al., 2005). Apart from its graphical depiction of variable interactions, this technique has the added advantage of not being limited by the distributional assumptions required by traditional methods. The software used is SPSS Answer Tree 3.1. 
Early on a tool of computer science, decision trees (also known as classification trees) have been increasingly utilized in marketing and medicine. More recently, CHAID has been used several times to analyze variables in EEOC data focusing on hiring (McMahon, Hurley, Chan, Rumrill, \& Roessler, 2008), harassment (Shaw, Chan, \& McMahon, 2012), and discharge (Hurley, 2010).

Specifically, CHAID first establishes an independent variable which serves as an optimal predictor, one according to which the data are subdivided (Kass, 1980). Then chi-square significance levels are used to determine maximal explanatory value in terms of variance of the dependent variable. Each subgroup is re-analyzed independently, and the process continues until there are no longer any significant chi-square values available (Hawley, Diaz, \& Reid, 2009). The resulting classification tree provides a graphic, hierarchical display of variable interactions. The CHAID decision tree analysis is performed in order to examine the interaction of multiple significant variables, thus yielding information of more complexity than a standard Chi-Square analysis.

\section{Results}

Figures 1 and 2 show the CHAID decision tree, which graphically depicts the influences of the various independent variables on the dependent variable of merit outcome (closure). Table 1 shows the gain scores for the nodes/categories. Gains refer to the magnitude of relative statistical contribution to the value of the merit outcome. In the gains summary, one can see the proportional representation of the target category (here, merit closure) as it registers in the nodes.

These gains are rank ordered as index scores, with the score of the first node listed reflecting proportionately the most merit outcomes (Shaw, Chan, \& McMahon, 2012). In Table 1, Union 
Representation (Node 9) has the highest index score (126\%), meaning that the proportion of "regarded as disabled" complaints filed by this group is $26 \%$ higher than that of a comparison group, identified as the group/node on the list with an index score closest to $100.0 \%$. In general, the top index scores reveal the types of claimants who may be at high risk of experiencing discrimination on the basis of perceived disability. However, because the index scores for this study are not very high, more telling information can be found by analyzing the interaction effects of the CHAID "nodes," or end groups. These are unique clusters of variables which have significance for predicting merit outcome.

Findings show that the most significant predictor of merit resolution is the variable of Issue, $\left(X^{2}=58.08, \mathrm{df}=8, \mathrm{p}=0.000\right)$, that is, the nature of the complaint filed with the EEOC by the worker against the employer. The second most significant predictor of merit outcome was Industry Type. Since the purpose of the study is to examine the interaction effects of the predictor variables on the dependent variable of merit outcome, we see here in detail (Fig. 1) which clusters of variables (as CHAID nodes of information) emerge as significant predictors and with which other variables they interact.

The two Issues which were most predictive of merit outcome were Prohibited Medical Inquiry (Node 8, 62.5\%) and Testing (Node 7, 50.0\%). However, these Issues involved relatively few allegations: 512 for the former ( $1.3 \%$ of the total), and only 82 for the latter $(0.2 \%$ of the latter). Furthermore, these nodes, unlike the first six in the CHAID tree, did not yield any further information about other variables. The nodes which did yield information about interacting variables are as follows, in the order of their predictive significance for merit outcome. 
Qualification Standards (Node 6). Allegations of this issue had a merit resolution rate of $38.8 \%$ (2.9\% of total allegations for perceived disability). Industry type served as the second most significant predictor of merit closure, yielding two industry clusters. Within the issue of Qualification Standards, Mining, Manufacturing and Construction (Node 25) had a greater predictive value for merit outcome than did the group comprising Services, Transportation/Utilities, Public Administration and Finance (Node 24$)(46.9 \%$ vs. $30.3 \%)\left(\chi^{2}=\right.$ 32.7, $\mathrm{df}=1, \mathrm{p}=0.00$ ). There was no further branching of the CHAID tree from either of these nodes, that is, no further interactive information of any significance was found by the program. However, Nodes 1 through 5 did yield further information beyond Industry type.

Hiring and Reinstatement (Node 3). Allegations involving this groups of issues had a merit resolution rate of $34.3 \%$ ( $11.6 \%$ of total allegations for perceived disability). Industry type served as the second most significant predictor of merit closure, yielding three industry clusters, the two most predictive of which yielded further branches: For the Manufacturing \& Agriculture group (Node 19; 39.8\% of merit outcome within the context of Hiring and Reinstatement), Race served as a further factor for merit outcome with the Whites and Other group (Node 37) having a significantly higher merit resolution than Asian-Americans and Hispanics (Node 36) (42.6\% vs. $35.3 \%)\left(\chi^{2}=11.1, \mathrm{df}=1, \mathrm{p}<0.012\right)$. (Put differently, if the issue group is Hiring and Reinstatement and the Industry group is Manufacturing and Agriculture, it then matters what the prominent race factors are, in this case Whites and Other having a higher rate of merit outcome in the context of the interaction of the given issues and industries.) For the Transportation/Utilities, Public Administration and Finance cluster (Node 18; 31.3\% of merit outcome for the given issue), Age served as an additional predictor with the group comprising $\leq$ 
29,30 s, 50s, \& $60+$ having a higher merit resolution rate than the 40 s age category $(34.3 \%$ vs. $25.9 \%)\left(\chi^{2}=10.5, \mathrm{df}=1, \mathrm{p}<0.036\right)$

Demotion and Job Assignment (Node 4). Allegations of this group of issues had a merit resolution rate of $29.8 \%$ (4.3\% of total allegations for perceived disability). Industry type again served as the second most predictor of merit closure, yielding two industry clusters. For the Services, Transportation/Utilities \& Public Administration (25.0\% of merit outcomes within the given issue), Race served as a further factor for merit outcome with Whites and Hispanics having significantly higher merit resolution than Asian-Americans and Hispanics (28.7\% vs. 19.3\%) $\left(\chi^{2}\right.$ $=9.6 \%, \mathrm{df}=1, \mathrm{p}<0.029)$. For the Finance, Insurance, Real Estate, and Construction cluster (34.8\% of merit outcome for the given issue), Issue re-emerged as a variable to serve as an additional predictor with the Job Classification \& Assignment group having a higher merit resolution rate than that for Demotion, and Benefits/Pension (39.9\% vs. 30.2\%). That is to say, within the Finance group of industries, the Job Classification and Assignment group of issues had a specific significance in addition to the overall significance of Demotion and Job Assignment for this entire CHAID branch.

Terms and Conditions/Early Retirement (Node 1). Allegations of this group of issues had a merit resolution rate of $26.6 \%$ (26.9\% of total allegations for perceived disability). Industry type served as the second most significant predictor of merit closure status, yielding four industry clusters (in order of predictive significance for merit outcome within the context of the given issues): Transportation/Utilities, Mining, \& Construction (Node 11; 29.3\%); Wholesale/Retail \& Manufacturing (Node 13; 26.7\%); Services, Finance, \& Real Estate (Node 10; 24.4\%); and Public Administration \& Agriculture (Node 12; 20.3\%). Only Nodes 10 and 12 
yielded further nodes of information, detailed as follows: For the Services, Finance, \& Real Estate group (Node 10; $24.4 \%$ of merit outcome for the given issues), Gender (Nodes $26 \& 27$ ) served as a further factor for merit closure with females having a significantly higher merit resolution $(26.4 \%$ vs. $21.1 \%)\left(\chi^{2}=9.6, \mathrm{df}=1, \mathrm{p}<0.006\right)$. For the Public Administration \& Agriculture cluster (20.3\% of merit outcomes for the given issues), Race (Nodes 28 \& 29) served as an additional predictor with Asian-Americans, Whites, and Hispanics having a higher merit resolution than the other race categories $(22.4 \%$ vs. $12.4 \%)\left(\chi^{2}=9.0, \mathrm{df}=1, \mathrm{p}<0.04\right)$.

Discharge and Suspension (Node 2). Allegations involving this issue group had a merit resolution of $22.7 \%$ ( $40.2 \%$ of total allegations for perceived disability). Industry once again served as the second most significant predictor of merit closure yielding two industry clusters (in order of predictive significance for merit outcome within the context of the given issues): Wholesale/Retail, Manufacturing \& Construction (Node 15; 22.2\% of merit outcome for the given issues) and Services, Transportation/Utilities, \& Public Administration (Node 14; $20.2 \%$ of merit outcome for the given issues). For the Services group, Race served as a further factor for predicting merit closure with Whites having a significantly higher merit resolution than AsianAmericans and Hispanics (21.4\% vs. $17.8 \%)\left(\chi^{2}=10.8, \mathrm{df}=1, \mathrm{p}<0.01\right)$. For the Wholesale/Retail cluster, Age served as an additional predictor with both the youngest $(\leq 29)$ and oldest $(60+)$ worker categories having a higher merit resolution than the other age categories $(27.1 \%$ vs. $21.1 \%)\left(\chi^{2}=15.1, \mathrm{df}=1, \mathrm{p}<0.00\right)$.

Harassment and Discipline (Node 5). Allegations involving this group of issues had a merit resolution rate of $20.9 \%$ (12.2\% of total allegations for perceived disability.) Industry again served as the second most significant predictor of merit closure, yielding two industry clusters, 
Transportation/Utilities, Finance, \& Real Estate (Node 23; 23.8\% of merit outcome for the given issues) and Services, Public Administration, \& Wholesale/Retail (Node 22; 18.9\% of merit outcome for the given issues). For the Transportation cluster, Age served as a further factor for predicting merit closure with the groups $\leq 29,30 \mathrm{~s}$, and 50 s having a significantly higher merit resolution than the groups $40-49$ and $60+(26.6 \%$ vs. $19.0 \%)\left(\chi^{2}=13.8, \mathrm{df}=1, \mathrm{p}<0.006\right)$. For the Services cluster, Age again served as an additional predictor with the groups $\leq 29,40-49$, and $60+$ having a higher merit resolution than the other age categories $(22.2 \%$ vs. $15.7 \%)\left(\chi^{2}=\right.$ $19.5, \mathrm{df}=1, \mathrm{p}=0.00)$.

\section{Discussion}

This study examined the effects of the interaction of variables pertaining to perceived disability claims contained in the EEOC database and the differential effects of these interactions on the outcome of Merit Closure. One research question was posed : Which independent variables serve as predictors of Merit Closure for individuals regarded as having a disability? The relevant independent variables are: Claimant (worker) Age, Race, Gender; Industry Type, Employer Size and Issue (grievance). CHAID analysis showed that the most significant predictor of Merit Closure (the dependent variable) was Issue, followed by Industry Type, which yielded information about interactions with Age or Race or Gender, and, in one case, Issue again. What this reappearance of the Issue variable (see Diagram 1: Nodes 40, 41) indicates is that

within the Finance group of industries, the Job Classification and Assignment group of issues had a specific significance in addition to the overall CHAID branching. (See Wilkerson (1992) on the "re-emergence" of a CHAID variable in the decision tree). Each variable in the tree significantly affects the one above it. That is to say, the effect of Merit Closure depends on the 
Issues, which in turn depends on the Industry type and so on. If Issues and Industry type are statistically significant, then they will lead to merit resolution in favor of the charging party. This is consistent with the stated purpose of the study, namely, to consider, through the use of CHAID, the interactions of the predictor variables which influenced the decisions of the EEOC as to the merit of allegations filed by workers on the basis of perceived disability discrimination. These interactions are discussed in detail below.

Among people filing ADA complaints based on perceived disabilities, merit outcomes were most associated with complaints of hiring/reinstatement discrimination, especially in the industries of manufacturing and agriculture, especially when claimants were white. Hiring has been shown to be an easier allegation to substantiate than the four other primary issues (discharge/constructive discharge, reasonable accommodations, terms/conditions of employment, and intimidation/harassment), and employers need to be aware of that to prevent this allegation (McMahon, Hurley, et al, 2008). Merit outcomes were second most associated with complaints of discrimination based on Discharge, especially in the industries of wholesale, retail, and manufacturing and more especially when the plaintiffs were from the youngest $(\leq 29)$ and the oldest (60+) age groups. Claimants have less success with the allegation of Discharge since employers can appeal to poor worker performance, loss of job qualifications, adverse economic conditions ostensibly necessitating layoffs, and other developments (Hurley, 2010). The foregoing suggests that a psycho-educational intervention with employers regarding Hiring should focus on Manufacturing and Agriculture concerns, while one regarding Discharge, the most salient of all Issues for the perceived disability database, should focus on the wholesale, retail, and manufacturing industries with a special emphasis on the youngest and oldest workers in each case. 
The third most significant interaction of Issue with Industry Type as determined by ChiSquare computation, is that of Terms \& Conditions and Early Retirement Incentive yielding industry clusters the most significant of which in terms of combined predictive value for merit outcome were Transportation/Utilities, Mining, and Construction. These broke down further into Gender with Females predominant. As examples of Terms and Condition, the EEOC codebook lists "assignment to unpleasant work stations or failure to provide adequate tools or supplies; inequities in shift assignment or vacation preferences; or restriction as to mode of dress or appearance" (EEOC, 2003). Both of these issues indicate coercive or at least dissuasive actions on the part of employers. The fact that most claims came from females in largely physical jobs suggest that management may be trying to take advantage of a cultural stereotype to pressure "the weaker sex" in the context of comparatively heavy labor, perhaps reasoning that forcing them out this way might be less likely to lead to formal complaints than if outright discharge were attempted. In the case of Public Administration/Agriculture, Race was the significant breakdown node, with the group comprising Asian-Americans, Hispanics, and Other predominating slightly over White claimants. It may be that management's coercive/dissuasive tactics were thought more likely to succeed in these industries because of less perceived racial/ethnic solidarity. This is highly speculative, of course, but it would be interesting to learn more about differential attitudes regarding gender and race (as well as age) as they pertain to the management of various industries.

The fourth most significant breakdown to Industry type involved Qualification Standards, which is described by the EEOC as "discrimination with respect to the factors for employment, referral, promotion, admission to membership in a labor organization, training, or assignment to a job or class of job" (EEOC, 2003). From this breakdown, two groups of industries emerged, of 
which the Manufacturing/Mining/ Construction complex predominated. Allegations of Qualification Standards in the context of perceived disability were relatively small in number $(2.9 \% ; \mathrm{n}=1135)$, and the definitional reach of the issue is so broad that there is not much basis for meaningful speculation, although it is interesting that the industries where it is most prominent all involve manual labor.

Next in significance was the node of Demotion/Assignment, which broke down more notably to the cluster of Finance, Real Estate, and Construction and then further to a reemergence of Issue, the most frequent being Job Classification and Assignment. The latter is much more frequent than the former and refers to the "designation of an employee to [a] less desirable duty, shift or work location" (EEOC, 2003). This reappearance of the Issue variable in the tree means that, with the Finance group of industries, the Job Classification and Assignment group of issues had a specific significance above the overall significance of Demotion and Job Assignment for that entire CHAID branch. The repetition of a variable (Issue) in the same CHAID branch (see Figure 1) has been judged acceptable on the basis of parsimony, since the alternative would be a more complicated and unhelpful splitting (Wilkinson, 1992). Economic decline could explain, at least partially, the prominence of Demotion here as this action involves pay cuts and reduced benefits. Finally, the node of Harassment/Discipline broke down to the Industry cluster of Health care services, Public Administration, Wholesale and Retail, yielding Age as most significant, with no clear pattern of meaning for the latter.

The theories of stigma and causal attribution are relevant to the research question posed. Ageism, racism, and sexism could all amplify the stigma of disability consciously and likewise contribute to implicit bias pertinent to age, race and gender. Regarding Respondent 
characteristics, some areas of the country, some industries, and some larger or smaller companies could, for various reasons directly related to a given characteristic, manifest more or less conscious stigmatizing behavior and/or implicit bias. Likewise, certain issues by their nature might bring stigma or unconscious prejudice into play. Finally, the matter of actual discrimination, as determined by merit closure decisions, is logically either conscious and/or unconscious, and the theories of stigma and causal attribution can account for these respective cognitions/behaviors.

\section{Conclusion}

This study examined the effects of variables pertaining to perceived disability claims contained in the Integrated Mission System section of the EEOC database. Specifically, this includes all ADA-related discrimination complaints filed from the initial implementation of the ADA through the date when the data were submitted to researchers in 2009. It further investigated the extent to which merit outcomes in these cases could be predicted from the interactions among independent variables of worker age, race and gender; the allegation of impropriety (Issue); company size, and Industry Type. Specifically, merit outcome depended on the issues of: Qualification Standards, but mainly in manufacturing, mining and construction; Hiring and Reinstatement, especially for White and Other claimants in manufacturing and agriculture; Demotion and Job Assignment, especially for claimants working in the finance, insurance, real estate, and construction industries; Terms and Conditions, especially for female claimants in the services and finance industries, as well as Asian-Americans, Whites, and Hispanics in public administration; Discharge, especially for Asian-Americans and Hispanics in the Transportation and Utilities industries, as well as the youngest $(\leq 29)$ and oldest $(60+)$ 
claimants in wholesale, retail, manufacturing, mining, and construction; and finally, Harassment, especially in the transportation, utilities, and finance industries for the age groups of $\leq 29,30$ s, and 50s.

It was determined that these variables do predict merit outcome, and that the most significant one in this regard is that of Issue, followed by Industry Type. While Discharge was the most frequent allegation, Hiring had proportionally more merit outcomes associated with it. For employers, this implies that they should be especially mindful of behaviors that could be construed as discriminatory by applicants.

If EEOC interviewers were to add SES question as they compiled information to expand the database, new insights into the sociological dynamics of disability discrimination in the workplace could be gained. As mentioned earlier, in their study of disability and poverty and the effect on access to legal services in Southern Pennsylvania, Rulli and Leckerman (2005) were able to make inferences of poverty based on certain indices of it from court records. It would be helpful if an item on future EEOC surveys addressed the socio-economic status of claimants.

Another limitation of this study is that there is no information in the database about disability types for the alternate prongs. Potentially revealing and useful data might emerge if we could compare perceived and actual (first prong) disability claims made by individuals with, e.g., cancer, HIV+/AIDS, traumatic brain injury and psychiatric syndromes. As an example, concerning the most frequent Issue, Discharge, it would be useful to know how cognitive errors inform the decision to terminate an employee.

Based on CHAID analysis, the following foci for psycho-educational interventions could be: White workers in Manufacturing and Agriculture who may have a higher rate of experiencing 
hiring discrimination; the youngest and oldest workers in Wholesale/Retail, Manufacturing, Mining, and Construction who may risk being unfairly discharged; workers in Transportation, Utilities and Mining who may have experienced discrimination on the basis of terms and conditions of employment; workers in Finance Services, Insurance and Real Estate who may have experienced demotion discrimination; and workers in Transportation, Utilities, Finance, and Real Estate who may experience harassment.

To gain a greater insight into the phenomenon of workplace discrimination on the basis of perceived disability, more information is needed. Specifically, nothing is known from the database about either the physical or mental conditions of the claimants for this group (as opposed to that of "actual," documented disability claimants). Also, socio-economic status for the entire population in the IMS is unknown.

Even though "regarded as disabled" claims are only about 10\% of total claims, 34,222 is a considerable number of allegations, and it behooves disability professionals to understand the social psychological forces behind the phenomenon of perceived discrimination, not just to inform psycho-educational intervention with targeted employers regarding this issue, but to contribute to a broader insight into prejudice against people with disabilities in general, so as to improve the overall effort to make the public aware of this injustice and how it may be remedied. 


\section{References}

An, S., Roessler, R.T., \& McMahon, B.T. (2011). Workplace discrimination and Americans with psychiatric disabilities: A comparative study. Rehabilitation Counseling Bulletin, 55 (1), 7-19.

Ara, A. (2010). The ADA Amendments Act of 2008: Do the Amendments cure the interpretation problems of perceived disabilities? Santa Clara Law Review, 50, 255.

Berger, A.M. \& Berger, C.R. (2004). Data mining as a tool for research and knowledge development in nursing. CIN: Computers, Informatics, Nursing, 22 (3), 123-131.

Bishop, M., Stenhoff, D.M., Bradley, K.D., \& Allen, C.A. (2007). The differential effect of epilepsy labels on employer perceptions: Report of a pilot study. Epilepsy and Behavior, $11,351-356$.

Blair, I.V. (2002). Malleability of automatic stereotypes and prejudice. Personality and Social Psychology Review, 6 (3), 242-261.

Blanck, P.D. \& Berven, H.M. (1999). Evidence of disability after Daubert. Psychology, Public Policy \& Law, 5(1), 16-40. 
Brown, J.O. (1997). Some thoughts about social perception and employment discrimination law. Emory Law Journal, 46, 1487-1497.

Chan, F. Cheing, G. Chan, J., Rosenthal, D.A., \& Chromister, J. (2006). Predicting employment outcomes of rehabilitation clients with orthopedic disabilities: A CHAID analysis. Disability and Rehabilitation, 28 (5), 257-270.

Chen, S., Ma, L. \& Zhang, J-X. (2011). Chinese undergraduates explicit and implicit attitudes toward persons with disabilities. Rehabilitation Counseling Bulletin, 55 (2), 38-45.

Courtwright, A.M. (2009). Justice, stigma, and the new epidemiology of health disparities. Bioethics, 23, 90-96.

Dalgin, R.S. \& Gilbride, D. (2003). Perspectives of people with psychiatric disabilities on employment disclosure. Psychiatric Rehabilitation Journal, 26 (3), 306-310.

Dasgupta, N. \& Greenwald, A.G. (2001). On the malleability of automatic attitudes: Combatting automatic prejudice with images of admired and disliked individuals. Journal of Personality and Social Psychology, 81, (5). 800-814.

Draper, W.R., Reid, C.A., \& McMahon, B.T. (2011). Workplace discrimination and the perception of disability. Rehabilitation Counseling Bulletin, 55(1), 29-37.

Fazio, R.H. \& Olson, M.A. (2003). Implicit measures in social cognition research: Their meaning and use. Annual Review of Psychology, 54, 297-327.

Georgetown University EEG/ERP Laboratory, n.d. The method of event-related brain potentials. http://brainlang.georgetown.edu/erplab.htm 
Goffman, E. (1963). Stigma: Notes on the management of spoiled identity. Englewood Cliffs, N.J.: Prentice Hall.

Greenwald, A.G., McGhee, D.E., \& Schwartz, J.L. (1998). Measuring the individual differences in implicit cognition: The Implicit Association Test. Journal of Personality and Social Psychology, 74 (6), 1464-1480.

Hawley, C.E., Diaz, S., \& Reid, C. (2009). Healthcare employees' progression through disability benefits. Work, 34 (1), 53-66.

Hewstone, M. (1989). Causal attribution: From cognitive processes to collective beliefs (Oxford, UK: Blackwell).

Horner, S.B., Fireman, G.D., \& Wang, E.W. (2010). The relation of student behavior, peer status, race, and gender to decisions about school discipline using CHAID decision trees and regression modeling. Journal of School Psychology, 48, 135-161.

Huber, L.P., Johnson, R.N., \& Kohli, R. (2006). Naming racism: A conceptual look at internalized racism in U.S. schools. Chicago-Latino Law Review, 26, 183.

Hurley, J.E. (2010). Merit determinants of ADA Title I. allegations involving discharge: Implications for human resource management and development. Advances in Developing Human Resources, 12 (4), 466-483.

Kass, G.V. (1980). An exploratory technique for investigating large quantities of categorical data. Applied Statistics, 29 (2), 119-127. 
Kawakami, K., Dovidio, J.F., Moll, J., Hermsen, S., \& Russin, A. (2000). Just say No (to stereotyping): Effects of training in the negation of stereotypic associations on stereotypic activation. Journal of Pesonality and Social Psychology, 78 (5), 871-888.

Krieger, L.H. \& Fiske, S.T. (2006). Behavioral realism in employment discrimination: Implicit bias and disparate treatment. California Law Review, 94: 997-1062.

Larson, D. (2008) Unconsciously regarded as disabled: Implicit bias and the regarded-as prong of the ADA. UCLA Law Review, 56, 451.

Link, B.G., \& Phelan, J.C. (2001). Conceptualizing stigma. Annual Review of Sociology, 27, $363-385$.

McCabe, R.M., Adomavicius, G., Johnson, P.E., Ramsey, G., Rund, E., Rush, W.A., O’Connor, P.J., \& Sperl-Hillen, J. (2008). Using data mining to predict errors in chronic disease care. In Henriksen K. et al. (Eds.) Advances in patient safety: New directions and alternative approaches (Vol. 3). Rockville, MD: Agency for Healthcare Research and Quality. http://www.ncbi.nlm.gov/books/NBK43675/

McMahon, B.T., Hurley, J.E., Chan, F., Rumrill, P.D., Jr., Roessler, R. (2008). Drivers of hiring discrimination for individuals with disabilities. Journal of Occupational Rehabilitation, 18 (2), Epub 2008 Apr. 30.

McMahon, B.T. (2005). Workplace discrimination and HIV/AIDS: The National EEOC ADA Research Project. Work, 25 (1), 34-48.

Milner, B., Corkin, S., \& Tueber, H.L. (1968). Further analysis of the hippocampal amnesic syndrome: Fourteen year follow-up study of H.M. Neuropsychologica, 6, 215-234. 
National Poverty Center, University of Michigan (2008). Poverty in the United States:

Frequently asked questions. http://www.npc.umich.edu/poverty/ Accessed 9/24/2009.

Phelps, E.A., O’Connor, K.J., Cunningham, W.A., Funayama, E.S., Gatenby, J.C., Gore, J.C., \& Banaji, M.R. (2000). Performance on indirect measures of race evaluation predicts amygdala activation. Journal of Cognitive Neuroscience, 12 (5), 729-738.

Press, L.I., Rogers, M.S., \& Shure, G.H. (1969). An interactive technique for the analysis of multivariate data. Behavioral Science, 14, 364-370.

Reiner, B. (2010). Uncovering and improving upon the inherent deficiencies of radiology reporting through data mining. Journal of Digital Imaging, 23 (2), 109-118.

Reutter, L.I., Stewart, M.J., Veenstra, G., Love, R., Raphael, D., \& Makwarimba, E. (2009). "Who do they think we are, anyway?": Perceptions of and responses to poverty stigma. Qualitative Health Research, 19, 297-311.

Ritscher, J.B., Otilingma, P.G., \& Grajales, M. (2003). Internalized stigma of mental illness: Psychometric properties of a new measure. Psychiatry Research, 121: 31-49.

Robinson v. Global Marine Drilling. 101 F.3d, 35 (5 ${ }^{\text {th }}$ Circuit, 1996).

Ross, M.W., \& Rossen, B.R.S. (1996). Measurement and correlates of internalized homophobia: A factor analytic study. Journal of Clinical Psychology, 52, 15-21.

Rowen, C.J., \& Malcolm, J.P. (2002). Correlates of internalized homophobia and homosexual indentity formation in a sample of gay men. Journal of Homophobia, 43, 77. 
Rudman, L.A., Ashmore, R.D., \& Gary M.L. (2001). “Unlearning” automatic biases: The malleability of implicit prejudice and stereotypes. Journal of Personality and Social Psychology, 81, (5), 856-868.

Rulli, L.S. \& Leckerman, J.A. (2005). Unfinished business: The fading promise of ADA enforcement in the Federal courts under Title I. and its impact on the poor. Journal of Gender, Race, and Justice, 8, 595.

Rutter, M. (2006). Implications of resilience concepts for scientific understanding. Annals of the New York Academy of Sciences, 1094, 1-12.

Scambler, G. (2009). Health-related stigma. Sociology of Health and Illness, 31(3), 441-455.

Shaw, L.R., Chan, F., \& McMahon, B.T., (2012). Intersectionality and disability harassment: The interactive effects of disability, race, age, and gender. Rehabilitation Counseling Bulletin, 55 (2), 82-91.

Shean, G. (2001). A critical look at the assumptions of cognitive therapy. Psychiatry, 64 (2), 158-164.

Shevrin, H. (1996). Conscious and unconscious processes: Psychodynamic, cognitive and neurophysiological convergences. New York: Guilford Press.

Smith, E.C. \& Grawe, K. (2003). What makes psychotherapy sessions productive? A new approach to bridging the gap between process research and practice. Clinical Psychology and Psychotherapy, 10, 275-285. 
Swartz, B.E. \& Goldensohn, E.S. (1998). Timeline of the history of EEG and associated fields. Electroencephalography and Clinical Neurophysiology, 106, 173-176.

Travis, M.A. (2002). Perceived disabilities, social cognition, and "innocent mistakes." Vanderbilt Law Review, 55, 481.

Tversky, A. \& Kahneman, D. (1974). Judgment under uncertainty: Heuristics and biases. Science 27 Sept.; 185 (4157), 1124-1131.

Vauth, R., Kleim, B., Wirtz, M., \& Corrigan, P.W. (2007). Self-efficacy and empowerment as outcomes of self-stigmatizing and coping in schizophrenia. Psychiatry Research, 150, 7180.

U.S. Equal Employment Opportunity Commission (EEOC) (2003). Codebook for the Charge Data System. Author: Washington, D.C.

Welte, J.W., Barnes, G.M., Wieczorek, W.F., \& Tidwell, M.C. (2004). Gambling participation and pathology in the U.S.: A sociodemographic analysis using classification trees. Addictive Behaviors, 29, 983-989.

Wilkinson, L. (1992). Text structured data analysis: AID, CHAID and CART. Conference presentation. http://www.cs.uic.edu/ wilkinson/Publications/c\&rtrees.pdf

Williams, J.K. \& Themanson, J.R. (2010). Neural correlates of the implicit association test: Evidence for semantic and emotional processing. Social Cognitive and Affective Neuroscience (advanced access). doi:10.1093/scan/nsq065. 


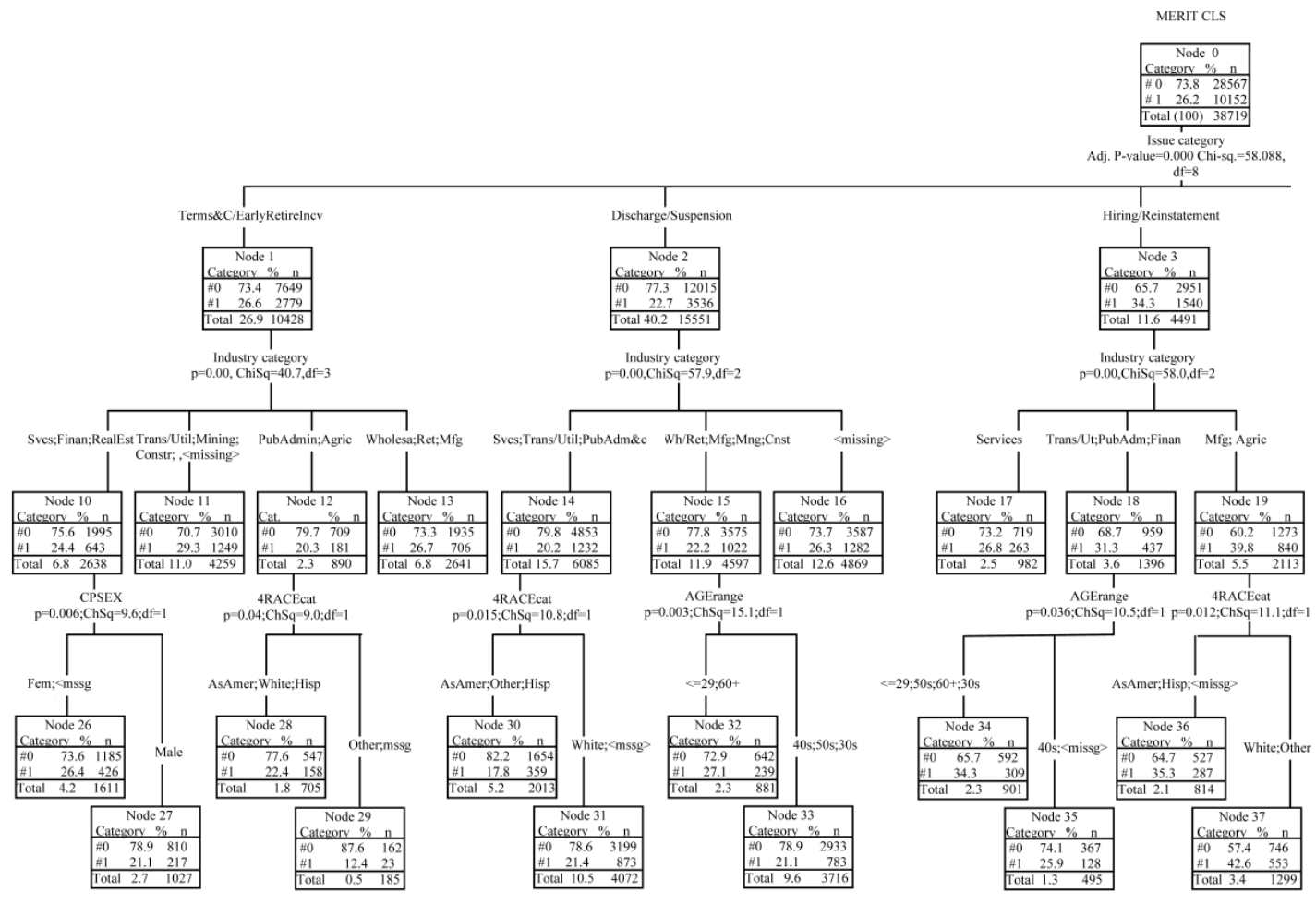

Figure 1. Split half view of left branch 


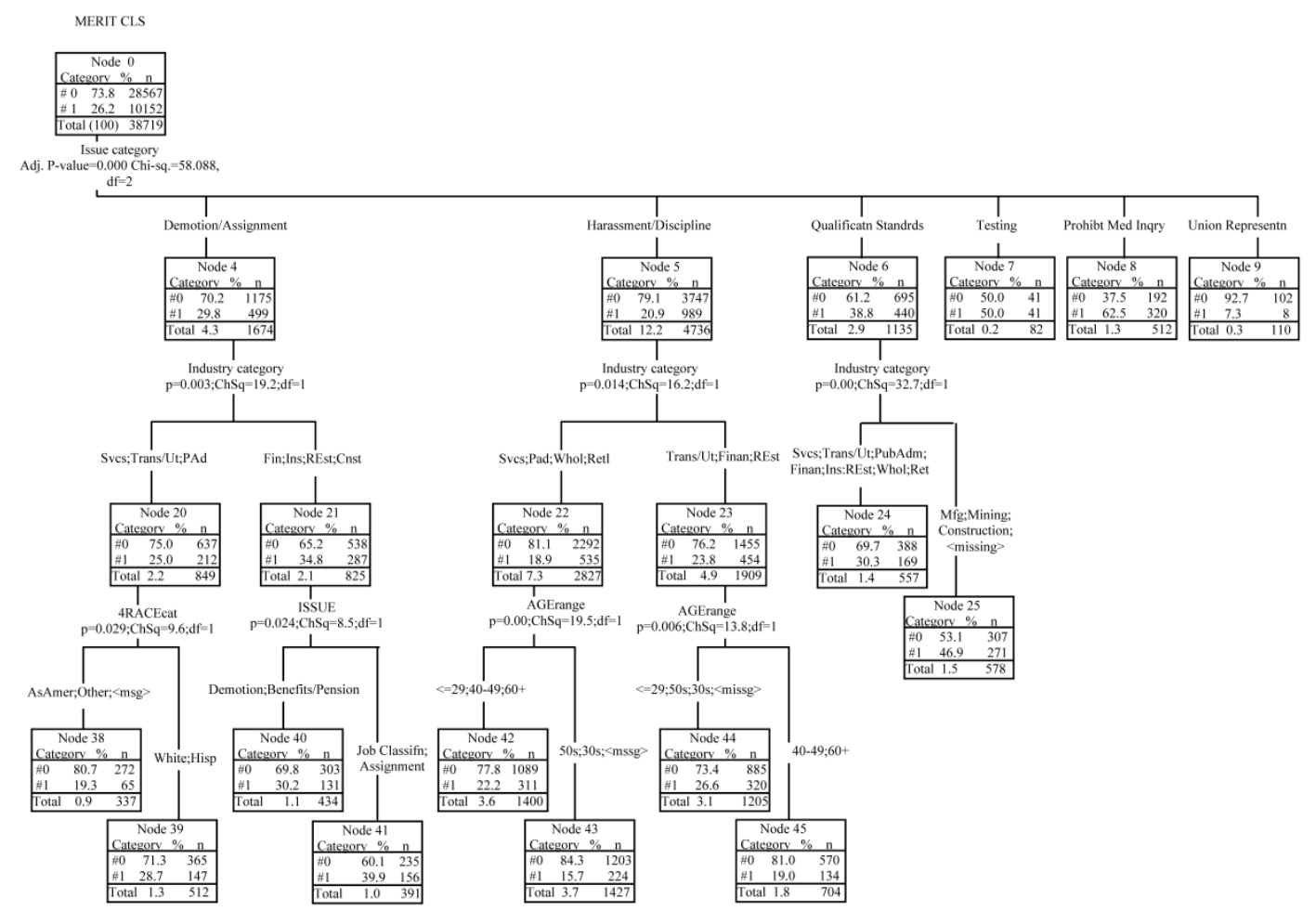

Figure 2. Split half view of right branch 
Table 1

Charging Party \& Employer Demographics

Variables

Frequency

Percentage

Gender

Male

20637

53.8

Female

17723

46.2

Ethnicity

African American

6582

20.8

Hispanic

2265

7.2

Other

2945

9.3

Caucasian

19878

62.8

Age

$\leq 29$

3381

9.4

30-39

8769

24.4

40-49

12462

34.7

50-59

8413

23.4

$\geq 60$

2939

8.2

Industry

Agriculture

264

1.0

Mining \& Construction

1136

4.2

Manufacturing

6050

22.3

Transportation \& Utilities

3090

11.4

Wholesale \& Retail Trade

3672

13.5

Financial, Insurance, Real Estate

1248

4.6

Health Care Services

8963

33.0

Public Administration

2753

10.1 


\section{Employer Size}

$15-100$

12710

34.5

$101-200$

4368

11.9

$201-500$

4326

11.8

$500+$

15407

41.9

Issues (Grievance)

Discharge

14282

36.9

Reasonable Accommodation

3161

8.2

Harassment

2507

6.5

Terms/Conditions

3684

9.5

Hiring

3601

9.3

Discipline

1174

3.0

Less than $3 \%$ of allegations filed

10310

26.6 
Table 2

Merit Closure Status

\section{Frequency Percentage}

\begin{tabular}{lcc}
\hline Non-Merit & 28567 & 73.8 \\
Merit & 10152 & 26.2 \\
\hline Total & 38719 & 100.0 \\
\hline
\end{tabular}


Table 3: Gains summary scores

Node-by-node statistics

Node $\quad$ Node: $\mathrm{N} \quad$ Node: $\% \quad$ Gain: $\mathrm{N} \quad$ Gain (\%) Index: (\%) Resp (\%)

$\begin{array}{lllllll}9 & 110 & 0.3 & 102 & 0.4 & 125.7 & 92.7 \\ 29 & 185 & 0.5 & 162 & 0.6 & 118.7 & 87.6 \\ 43 & 1427 & 3.7 & 1203 & 4.2 & 114.3 & 84.3 \\ 30 & 2013 & 5.2 & 1654 & 5.8 & 111.4 & 82.2 \\ 45 & 704 & 1.8 & 570 & 2.0 & 109.7 & 81.0 \\ 38 & 337 & 0.9 & 272 & 1.0 & 109.4 & 80.7 \\ 33 & 3716 & 9.6 & 2933 & 10.3 & 107.0 & 78.9 \\ 27 & 1027 & 2.7 & 810 & 2.8 & 106.9 & 78.9 \\ 31 & 4072 & 10.5 & 3199 & 11.2 & 106.5 & 78.6 \\ 42 & 1400 & 3.6 & 1089 & 3.8 & 105.4 & 77.8 \\ 28 & 705 & 1.8 & 547 & 1.9 & 105.2 & 77.6 \\ 35 & 495 & 1.3 & 367 & 1.3 & 100.5 & 74.1 \\ 16 & 4869 & 12.6 & 3587 & 12.6 & 99.9 & 73.7 \\ 26 & 1611 & 4.2 & 1185 & 4.1 & 99.7 & 73.6 \\ 44 & 1205 & 3.1 & 885 & 3.1 & 99.5 & 73.4 \\ 13 & 2641 & 6.8 & 1935 & 6.8 & 99.3 & 73.3 \\ 17 & 982 & 2.5 & 719 & 2.5 & 99.2 & 73.2 \\ 39 & 512 & 2.6 & 642 & 2.2 & 98.8 & 72.9 \\ 11 & 1.3 & 365 & 1.3 & 96.6 & 71.3 \\ 39 & 11.0 & 3010 & 10.5 & 95.8 & 70.7\end{array}$




$\begin{array}{lllllll}40 & 434 & 1.1 & 303 & 1.1 & 94.6 & 69.8 \\ 24 & 557 & 1.4 & 388 & 1.4 & 94.6 & 69.8 \\ 34 & 901 & 2.3 & 592 & 2.1 & 89.1 & 65.7 \\ 36 & 814 & 2.1 & 527 & 1.8 & 87.7 & 64.7 \\ 41 & 391 & 1.0 & 235 & 0.8 & 81.5 & 60.1 \\ 37 & 1299 & 3.4 & 74.6 & 2.6 & 77.8 & 57.4 \\ 25 & 578 & 1.5 & 307 & 1.1 & 72.0 & 53.1 \\ 7 & 82 & 0.2 & 41 & 0.1 & 67.8 & 50.0 \\ 8 & 512 & 1.3 & 192 & 0.7 & 50.8 & 37.5\end{array}$

In versions prior to Answer Tree 3.0, the Gains column was known as Responses and vice-versa. 


\section{Chapter 5}

\section{Conclusion}

The characteristics of perceived and historical disability claimants (and the corresponding employer-defendants) have been examined in order to see to what extent discrimination has occurred against these claimants as compared to those in the "actual", "standard" documented disability group. Statistical analysis shows proportionally greater merit resolution for both groups of alternate-prong cases compared to standard cases. The discrimination involved in these nonstandard cases is not necessarily a form of conscious stigmatizing (Travis, 2002). The significant level of merit resolutions in such cases reflects findings in empirical social psychology which indicate that implicit bias against people with disabilities is one of the strongest such biases in American society (Larson, 2008; Greenwald and Krieger, 2006). The fact that people with just minor, non-disabling impairments can be subjected to workplace discrimination underscores the impact of workplace discrimination in general.

It has been proposed here that psycho-educational interventions with employers can be utilized by disability professionals to diminish such discrimination even though much of it may be unconscious. The viability of such interventions is based on the understanding that such bias is largely of a cognitive nature, involving unexamined, automatic thoughts that can be revealed

and disputed (Tversky and Kahneman, 1974; Kihlstrom, 1987; Travis, 2002; Beck and Dozois, 2011). 


\section{Summarizing the Alternate Prongs Articles}

The ADA developed three prongs of the definition of "disability" in order to reflect the reality that not only do current, "straightforward" disabilities exist, but also perceived and historical ones; that is, some individuals may be "regarded as" disabled by employers and others may just have a record of disability. The latter two aspects are considered disabilities based on societal prejudice rather than on an "actual," current condition. (The same individual may file multiple allegations based on the different prongs of the definition.) Three articles were written on these alternate prongs, two dealing with the perceived aspect and the other, with the historical:

Comparing and contrasting allegations of perceived disability with those of "actual", documented disability;

Comparing and contrasting allegations of historical disability with those of "actual", documented disability; and,

Demonstrating which factors predict merit resolution using a decision-tree analysis.

In Workplace Discrimination and the Perception of Disability (Draper, Reid, \& McMahon, 2010), the data suggest that individuals "regarded as" disabled were more likely to file allegations of discrimination against employers from the transportation industry, those employing 15-100 workers, or those located in the South. Perceived disability claimants were also more likely to file allegations of discrimination based on issues of discharge or hiring and less likely to do so on the basis of harassment or failure to provide reasonable accommodations. Specifically, the merit resolutions for perceived claims disproportionally exceeded those for 
"actual" claims ( $26.2 \%$ vs. $22.5 \%$, a statistically significant difference). Given the less obvious nature of perceived claims, it is a bit surprising that the more straightforward, currently documented cases would have a lower rate of merit closure.

Because employers have exaggerated the significance of many impairments, from tics to epilepsy to injuries, the aforementioned intervention should involve the idea of an "impairment spectrum," that is, a continuum of severity for injuries and disorders. This concept can help to counteract "one-size-fits-all" stereotyping and encourage focus on the more complex, realistic consideration of the particular case at hand. Even though employers can make "innocent mistakes" in this regard, they are still legally liable for them, as evidenced by Taylor vs. Pathmark Stores (1999), in which a worker with a minor injury was fired because the extent of impairment was blown out of proportion.

In Workplace Discrimination and the Record of Disability (Draper, Hawley, \& McMahon, forthcoming), the focus was on historical (rather than current) disability, although in some cases residual effects persist. Much of the theory involving causal attribution and stigma is also relevant to these cases, since it has been shown that employers often hold the worker's past disability against him or her, regardless of whether residua exist (Hewstone, 1989; Long, 2006; Gilbert, 2001). Merit resolutions for record-of-disability allegations proportionately exceeded those for documented disabilities by a statistically significant margin $(25.8 \%$ vs. $22.5 \%)$. This indicates an ongoing need for the overcoming of stereotypes based on past disabilities.

De-biasing interventions should be chosen especially for the Health Care/Social Assistance industries as well as Transportation/Warehousing since the data suggest a relatively higher level of "historical discrimination" in these sectors. As with the perceptual claimants, the 
concept of an impairment spectrum is applicable, for over time, a given individual may have moved toward the less severe part of the spectrum, even to the point of having no residual effects from the past disability.

In Perceptual Disability Claims: A decision-tree analysis (Draper, Hawley, \& McMahon, \& Reid, forthcoming), the "regarded as" claims were re-analyzed using the classification-tree analysis of Chi-Square Automatic Interaction Detection (CHAID). Unlike the first study, this one examined the effects of the interactions of predictor variables pertaining to the perceived disability claims and the differential effects of these interactions on merit outcome. The research question addressed was: What factors are associated with merit outcomes for people making ADA EEOC complaints of perceived discrimination? Because the emphasis is on the interactive effects of independent variables of age, race, gender, company size, industry involved, and issue (complaint), this study yields information of greater depth and complexity than the first and may serve to refine possible psychoeducational interventions of disability professionals with employers, with the aim of minimizing further discrimination of this type.

For perceived disability claims, $26.22 \%$ of overall charges had a merit outcome. CHAID results indicate the variable of claimant grievances (Issues) were the most significant predictor of merit resolution. The second most significant predictor of merit resolution was Industry Type. Further predictors of merit outcome were Age, Race, Gender, and, in one case, Issue again. The variable of Issue re-emerged to serve as an additional predictor with the Job Classification and Assignment group having a higher merit resolution rate than that for Demotion and Benefits/Pension. That is to say, within the Finance group of industries, the Job Classification 
and Assignment group of issues had a specific significance in addition to the overall significance of Demotion and Job Assignment for this entire CHAID branch.

The CHAID analysis of variable interactions between Issue and Industry Type shows that the Hiring/Reinstatement node and the Discharge/Suspension node are of roughly equal statistical significance. White and Other claimants in the Manufacturing and Agriculture fields were more likely than Asian-American and Hispanics (42.6\% vs. $35.3 \%$ ) to file Hiring allegations, while White claimants again predominated for allegations of Discharge 21.4\%, with Asian-American, Hispanic and Other not far behind with 17.8\%) but in the fields of Healthcare Services, Transportation/Utilities and Public Administration. The third most predictive interaction from Issue to Industry Type was that of Terms and Conditions, followed by Qualification Standards and Demotion/Assignment and finally, Harassment/Discipline.

These results suggest that a psycho-educational intervention with employers regarding Hiring should focus on Manufacturing and Agriculture concerns while one regarding Discharge, the most prominent of all issues for the perceived disability database, should focus on Wholesale, Retail, Manufacturing and Construction, with an emphasis on the youngest $(\leq 29)$ and oldest $(60+)$ workers for the latter group of industries

\section{Directions for Future Research}

Unfortunately, due to confidentiality requirements, the EEOC database only provides broad regional identifications for claimants, so there is some intrinsic uncertainty about the specific geographic concentration of workplace discrimination against people with disabilities. This means that if relevant issues are concentrated in one state or certain cities, the targeting of 
an intervention may be "off" if complementary research that may guide selection of locales is not done.

Other issues which will need to be addressed later include obtaining socio-economic status for all claimants, learning disability types for "prongs claimants," and investigating other cognitive errors and unconscious processes that may be in play in perceptual discrimination. The latter could involve continuing the useful interface of rehabilitation studies with that of social psychology and cognitive neuroscience. 


\section{References}

American Psychiatric Association (2010). Openness by friends, family, celebrities reduces stigma of mental illness. News release, May 3, 2010.

http://www.psych.org/MainMenu/Newsroom/NewsReleases/2010-News-Releases/Mental-

Health-Month-2010.aspx

Antonak, R.F., and Livneh, H. (2000). Measurement of attitudes towards persons with disabilities. Disabilities and Behavior, 22 (5), 211-224.

Ara, A. (2010). The ADA Amendments Act of 2008: Do the Amendments cure the interpretation problems of perceived disabilities? Santa Clara Law Review, 50, 255.

Au, K.W. and Man, D.W.K. (2006). Attitudes toward people with disabilities: A comparison between health care professionals and students. International Journal of Rehabilitation Research, 29 (2), 155-160.

Bagenstos, S.R. (2000). Subordination, stigma, and 'disability'. Virginia Law Review, 86, 397.

Bargh, J.A. \& Williams, E.L. (2006). The automaticity of social life. Current Directions in Psychological Science, 15, 1-4.

Beck, A.T. and Dozois, D.J.A. (2011). Cognitive therapy: Current status and future directions. Annual Review of Medicine, 62, 397-409. 
Corrigan, P.W. (1999). Lessons from social psychology on discrediting psychiatric stigma. American Psychologist, 54 (9), 765-776.

Courtwright, A.M. (2009). Justice, stigma, and the new epidemiology of health disparities. Bioethics, 23,(2), 90-96.

Eichhorn, L. (1999). Major litigation activities regarding major life activities: The failure of the 'disability' definition in the Americans with Disabilities Act of 1990. North Carolina Law Review, 77, 1405.

Goffman, E. (1963. Stigma: Notes on the management of spoiled identity. Englewood Cliffs, N.J.: Prentice Hall.

Greenwald, A.G. \& Krieger, L.H. (2006). Symposium on behavioral realism: Implicit bias: Scientific foundations. California Law Review, 94, 943.

Krieger, L.H. (1995). The content of our categories: A cognitive bias approach to discrimination and equal employment opportunity. Stanford Law Review, 47, 1161.

Larson, D. (2008). Unconsciously regarded as disabled: Implicit bias and the regarded-as prong of the ADA. UCLA Law Review, 56, 451.

Leahey, T.H. (2003). Herbert A. Simon: Nobel Prize in Economic Sciences, 1978. American Psychologist, 58, (9), 753-755.

Link, B.G. and Phelan, J.C. (2001). Conceptualizing stigma. Annual Review of Sociology, 27, 363-385. 
Long, A.B. (2008). Introducing the new and improved Americans with Disabilities Act: Assessing the ADA Amendments Act of 2008. Northwestern Law Review Colloquy, 103, 217.

McMahon, B.T., Hurley, J.E., West S.L., Chan F., Roessler, R., Rumrill, P.D., Jr. (2008). A comparison of EEOC closures involving hiring versus other prevalent discrimination under the Americans with Disabilities Act. Journal of Occupational Rehabilitation, 18, 106-111.

McMahon, B.T., Edwards, R., Rumrill, P.D., and Hursh, N. (2005). An overview of the national EEOC ADA research project. Work, 29, 1-7.

Pendo, E.A. (2003). Substantially limited justice?: The possibilities and limits of a new Rawlsian analysis of disability-based discrimination. St. John's Law Review, 77, 227.

Reissman, M.D. (2005). Traveling "to the farthest reaches of the ADA," or taking aim at employment discrimination on the basis of perceived disability. Cardozo Law Review, 26, 2121.

Reutter, L.I., Stewart, M.J., Veenstra, G., Love, R., Raphael, D., and Makwarimba, E. (2009). "Who do they think we are, anyway?": Perceptions of and responses to poverty stigma. Qualitative Health Research, 19, 297-311.

Rondon v. Walmart (N.D., 1998) WL 730843.

Ross, L. (1977). The intuitive psychologist and his shortcomings: Distortions in the attribution process. In L. Berkowitz (Ed.), Advances in experimental social psychology (vol.10). New York: Academic Press. 
Rubin, S.E. and Roessler, R.T. (2008). Foundations of the vocational rehabilitation process. $6^{\text {th }}$ Ed. Austin, TX: Pro-ed.

Rulli, L.S. and Leckerman, J.A. (2005) Unfinished business: The fading promise of ADA enforcement in the Federal courts under Title I. and its impact on the poor. Journal of Gender, Race, and Justice, 8, 595.

Sabini, J., Siepmann, M. and Stein, J. (2001). The really fundamental attribution error in social psychological research. Psychological Inquiry, 12 (1), 1-15.

Scambler, G. (2009). Health-related stigma. Sociology of health and illness, 31, 441-455.

School Board of Nassau County v. Arline (1987). 480 U.S. 273.

Shevrin, H. (1996). Conscious and unconscious processes: Psychodynamic, cognitive and neurophysiological convergences. New York: Guilford Press.

Taylor v. Pathmark Stores (1999). 177 F. 3d. 180.

Thornicroft, G., Rose, D., Dassam, A., and Sartorius, N. (2007). Stigma: Ignorance, prejudice, or discrimination? British Journal of Psychiatry, 190, 192-193.

Travis, M.A. (2002). Perceived disabilities, social cognition, and "innocent mistakes". Vanderbilt Law Review, 55, 481.

Tversky, A. and Kahneman, D. (1974). Judgment under uncertainty: Heuristics and biases. Science, 27 Sept.; 185 (4157), 1124-1131. 
U.S. Access Board (2009). The ADA Amendments Act of 2008. http://www.accessboard.gov/about/laws/ada-amendments.htm

U.S. Department of Justice ADA Home Page (2009). http://www.ada.gov/pubs/adastatute08mark.htm

U.S. Equal Employment Opportunity Commission (EEOC) (2005). The ADA: Your employment rights as an individual with a disability. http://www.eeoc.gov/facts/ada18.html

Westen, D. (1999). The scientific status of unconscious processes: Is Freud really dead? Journal of the American Psychoanalytic Association, 47, 1061-1106.

Wooten v. Farmland Foods (1995). 58 F. 3d 382; 1995 U.S. App. LEXIS 15902. 


\section{Vita}

William Draper is a citizen of the United States. He graduated from Virginia Commonwealth University in Richmond with a Bachelor's Degree in Psychology in 1983. Mr. Draper returned to the university system some years later and received a Master of Science degree in Rehabilitation Counseling, also from Virginia Commonwealth University, in 2005. He is currently unemployed. 